\title{
Lusioersily
}

\section{Multilayer nanoscale functionalization to treat disorders and enhance regeneration of bone tissue}

Ferreira, A. M., Tonda-Turo, C., Mancuso, E., \& Gentile, P. (2019). Multilayer nanoscale functionalization to treat disorders and enhance regeneration of bone tissue. Nanomedicine: Nanotechnology, Biology, and Medicine, 19, 22-38. https://doi.org/10.1016/j.nano.2019.03.009

Link to publication record in Ulster University Research Portal

\section{Published in:}

Nanomedicine: Nanotechnology, Biology, and Medicine

Publication Status:

Published (in print/issue): 01/07/2019

DOI:

10.1016/j.nano.2019.03.009

\section{Document Version}

Author Accepted version

\section{General rights}

Copyright for the publications made accessible via Ulster University's Research Portal is retained by the author(s) and / or other copyright owners and it is a condition of accessing these publications that users recognise and abide by the legal requirements associated with these rights.

\section{Take down policy}

The Research Portal is Ulster University's institutional repository that provides access to Ulster's research outputs. Every effort has been made to ensure that content in the Research Portal does not infringe any person's rights, or applicable UK laws. If you discover content in the Research Portal that you believe breaches copyright or violates any law, please contact pure-support@ulster.ac.uk. 
Multilayer nanoscale functionalisation to treat disorders and enhance regeneration of bone tissue

Ana Marina Ferreira, $\mathrm{PhD}^{1 \S}$, Chiara Tonda-Turo, $\mathrm{PhD}^{2 \S}$, Elena Mancuso, $\mathrm{PhD}^{3}$ and Piergiorgio Gentile, $\mathrm{PhD}^{1}$ *

${ }^{1}$ School of Engineering, Newcastle University. Claremont Road, Newcastle upon Tyne NE1 7RU, United Kingdom

${ }^{2}$ Department of Mechanical and Aerospace Engineering, Politecnico di Torino. Corso Duca degli Abruzzi 24, 10129 Turin, Italy

${ }^{3}$ Nanotechnology and Integrated Bio-Engineering Centre (NIBEC), Ulster University. Shore Road, Newtownabbey, BT37 0QB United Kingdom

${ }^{\S}$ Equally contribution; * Contact author e-mail: piergiorgio.gentile@ncl.ac.uk

Keywords: Layer-by-Layer assembly; nanocoatings; nanoencapsulation; bone regeneration; bone disorders.

\title{
Word count for Abstract: 157 \\ Word count for manuscript: 12570 \\ Number of References: 134 \\ Number of figures: 7 \\ Number of tables: 1 \\ Number of Supplementary online-only files, if any: 0
}

\begin{abstract}
text
The coatings application onto medical devices has experienced a continuous growth in the last few years. Medical device coating market is expected to grow at a CAGR of $5.16 \%$ to reach USD 10 million by 2023 due to the increasing geriatric population and the growing demand for continuous innovation. Layer-by-Layer (LbL) assembly represents a versatile method to modify the surface properties, in order to control cell interaction and thus enhance biological functions. Furthermore, LbL is environmentally friendly, able to coat all types of surfaces with the creation of homogenous film and to include and control the release of biomolecules/drugs. This feature review provides a critical overview on recent progresses in functionalizing materials by $\mathrm{LbL}$ assembly for bone regeneration and disorder treatment. An overview of emerging and visionary opportunities on LbL technologies and further combination with other existing methods used in biomedical field, are also discussed to evidence the new challenges and potential developments in bone regenerative medicine.
\end{abstract}

\section{Introduction}

Layer-by-Layer technique has been of great interest since 1930's, when Langmuir and Blodgett transferred insoluble monolayers from water surface to solid substrates ${ }^{[1]}$. Langmuir-Blodgett films and the build-up of multilayers by alternative adsorption of anionic and cationic polyelectrolytes have been adapted into different LbL methods to generate functional material and surface for a wide range of applications in different fields. Due to the limited availability of analysis technology and eventually awareness of those ones existing within the different fields, the evolution of LbL was slow until its (re)-discovery in the 1990s, 
when a full characterisation of the LbL thin multilayers and the use of robots and automated

Traditional LbL assembly consists in the adsorption of positive and negative charged polyelectrolytes onto a substrate, which has been requested by different fields where assemblies are built one layer at time ${ }^{[4]}$. Furthermore, LbL assembly exploits diffusion-driven kinetics by immersing the substrates into material solution(s) to facilitate the molecules adsorption onto the substrates, followed by washing/rinsing steps to remove not adsorbed material. Since these steps are tedious and time-consuming, technological efforts have been centered in order to overcome these practical issues by reducing the deposition time and assembly while controlling the coating surface properties ${ }^{[5]}$. These resulted in the use of automated machines with driving assembly technologies that enable a structured layering of materials rather than the solely and random molecules diffusion ${ }^{[6]}$. Traditional LbL assembly approach was adapted into unconventional and quasi-LbL approaches, in which the development of films is centered on the integration of different interdisciplinary fields for controlling the assembly at larger or smaller scale rather than looking to get deeper understanding of the film formation and properties at molecular level ${ }^{[2]}$. However, in this feature review, we will focus on those LbL assembly techniques that build sequentially coated surfaces or structures at nanoscale (below $1 \mu \mathrm{m}$ ) applied to regenerate or treat disorders concerning bone tissue. Among the different methods, the traditional immersive $\mathrm{LbL}$ is the most widely used assembly-based technology due to the simplicity of the dipping process for coating almost any geometry or size substrate, which makes this approach easily accessible. However, the possibility that unbound molecule residues, not fully removed during the washing steps subsequent to each deposition, limit its efficiency for practical and scale-up applications ${ }^{[3]}$. Improvements of this technique to speed up the assembly process include the promotion of faster kinetics by e.g. dewetting the deposited nanolayers ${ }^{[7]}{ }^{[8]}$. In the last decades, the use of alternative techniques such as spray and spin-assisted LbL, electromagnetic and fluidic has gained a lot of importance (Figure 1), particularly in the biomedical field. Moreover, LbL assembly has evolved from an academic curiosity into an opening technology to change industry (e.g. 3M applies LbL assembly as platform technology in electronics, energy and healthcare ${ }^{[9]}$. Particularly, in the last five years, research on LbL assemblies applied to bone tissue field has gained importance by nearly doubling the number of publications. By a simple key-word search on ISI Web of Knowledge database of topic terms such as "layer-by-layer bone" or "layer-by-layer bone regeneration" or "layer-bylayer bone nanoscale" or "layer-by-layer bone drug delivery", it is possible to appreciate that the number of publications (Figure 2) on LbL applied to bone regeneration and drug delivery is higher (since 2012, increased about 2.3 times) when compared to publications which studies LbL effects on bone at nanoscale (x 1.9). However, the first studies on material coatings by LbL for bone applications at nanoscale are dated back to the beginning of the new century ${ }^{[10,11]}$.

Bone disorders are ascribed to both traumatic and pathological events. To date, the main issues associated to bone trauma have to address low osteointegration of synthetic devices and poor bone regeneration in case of large bone defects. Bone is a complex and highly dynamic tissues composed by many actors which have to be orchestrated by a multifactorial methodology in order to achieve the ambitious goal of bone re-growth. LbL offers the unique 
opportunity to impart chemical, physical, biochemical, morphological and topographic features in a singular treatment as the versatility of the LbL technology allows to create a nanostructured surface morphology loading chemical and biochemical cues.

In this feature review, we propose an overview on the recent applications of LbL assembly for the functionalization at the nanoscale of bone-intended medical devices, describing in the last section a visionary perspective of a translational scale-up of this LbL technology for future research in the bone field.

\section{Change in topography for enhancing bone healing and regeneration}

Surface topography within few nanometers has been found to trigger specific responses in biological systems ${ }^{[12][13][14][15][16]}$. The majority of reported research on LbL assembly for bone tissue applications relates to the influence of multilayers made of natural polymers onto either polymeric or metal substrates on stem cells behaviour and osteogenesis.

The nature and organisation of the biomolecules or polyelectrolytes (i.e. chemical strucuture and molecular lenght of the deposited biomolecules) during the LbL assembly plays a key role in the topography and surface properties of the biomaterial, including surface wettability, roughness, etc ${ }^{[17,18]}$. Surface wettability tends to increase when incorporating hydrophilic polyelectrolytes, such as collagen, gelatin (GEL), chitosan (CHI), chondroitin sulfate (CS), hyaluronic acid (HA), for promoting ECM biomolecules absorption such as fibronectin, which can determine the initial cell attachment of osteoblasts ${ }^{[19]}$. In general, multilayered films made from highly hydrated polyelectrolytes yield very soft and gel-like films, which do not favor cells adhesion ${ }^{[17]}$. In order to modulate the mechanical properties of polylectrolytes multilayered (PEM) films, different strategies have been applied, and the most common ones include: a) ionic crosslinking by changing $\mathrm{pH}$ and ionic strenght ${ }^{[20]}$, chemical by incorporating crosslinkers (natural such as genipin or sinthetic like EDC), thiol or disulfide groups, photo-crosslinking, and physical through the incorporation of nanoparticles ${ }^{[17]}$. On this regard, by modifying the stiffness of the multilayerd films, cells response can varies to the rigidity of the underlying matrix as they exert forces on it, facilitating or preventing their migration, adhesion and spreading.

PEM films can grow either linearly or exponentially at different conditions. Their thickness is mostly related to the ability of the polyelectrolyte to up-take water, to the charge density and the affinity between pairs of polyelectrolyte with opposite charge ${ }^{[17]}$. Liu et al found in a recent work, that after depositing 6 layers, the thickness of the multilayers changed depending on the polyecetrolytes, obtaining 11.7 and $13.7 \mu \mathrm{m}$ for GEL/HA, 12.7 and $20.4 \mu \mathrm{m}$ for GEL/CS, 13.7 and $37.0 \mu \mathrm{m}$ for $\mathrm{CHI} / \mathrm{CS}$, and 16.7 and $19.3 \mu \mathrm{m}$ for $\mathrm{CHI} / \mathrm{HA}$ on flat and porous films ${ }^{[21]}$. These results suggest that molecules such as CHI, CS and HA promote thicker films when compared to GEL biomolecules. Polysaccharides rich in intra-molecules hydrogen bonds, such as chitosan, are rigid molecules with high intrinsic stiffness due to the high molecular size and conformation that do not chance significantly during the drying steps of the layer-by-layer ${ }^{[21,22]}$. However, biomolecules such as gelatin, are flexible due to the low molecular weight product of collagen degradation, consequently the molecular conformation can change significantly during the drying/wetting steps ${ }^{[23]}$. Thus, the film thickness may increase either linearly or exponentially with the deposited layers depending on the polymer conformation and the charge density. Surface charge density can affect polyelectrolytes 
adsorption such as proteins (depending on the pI, isoelectric point) during the wet steps, and ultimately cell response $\mathrm{e}^{[17]}$. The typical negatively charged functional groups of natural polyelectrolytes (proteins, polysaccharides, etc) includes carboxylic acid and sulfates; and as positively charged groups the most common are amines.

The use of specific biomolecules such as proteins, charged-polysaccharides (i.e. sulfated molecules) or GF within the nanocoating can instruct and orchestrate the cell behavior by either the surface chemical or mechanical properties, including stiffness and topography.Collagen is the main structural protein in bone, its molecules are high molecular size and conformation. Although, collagen type-I in acetic acid solution is mainly in the form of monomers, it has the ability to assemble into fibrils structures of $50 \mathrm{~nm}$ in diameter and several micrometers in length at physiological conditions ${ }^{[24]}$. The collagen-polyelectrolytes build-up into films and their thickness follow a linear growth regime with the successive layer depositions, leading to uniform and dense fiber network ${ }^{[25]}{ }^{[26]}{ }^{[27]}$. The dimensions of collagen fiber are usually between $150-300 \mathrm{~nm}$, this surface topography is not commonly observed for other polylectrolytes or proteins, which typically form aggregates with diameters ranged between $50-60 \mathrm{~nm}^{[26]}$. Moreover, molecules such as GAG's (i.e. hyaluronic acid, heparin, chondroitin sulfate) have been found to promote the assembling and formation of collagen fibers ${ }^{[28]}$. Particularly, sulfated GAGs such as CS , heparin (Hep), heparin sulfate have high affinity to growth factors (GFs) due to sulfate groups, these interfere with GFs that participate in the regulation of osteoblastic lineage (such as bFGF, TGF- $\beta 1$, BMP-2 and 3, IGF-II) ${ }^{[18]}$.

Other physico-chemical properties, such as polyelectrolyte concentration and charge density, can affect the final properties of the assembled multilayers. The $\mathrm{pH}$ and use of salts within the wetting steps have been shown to change frequency and dissipation energy shifts during the QCM monitoring of multilayers deposition ${ }^{[18]}$. The presence of high salt concentrations (i.e. $\mathrm{NaCl}$ in the deposition of chitosan and carrageenan) leads to more rigid films as the small ions promote a charge shielding effect over the charged groups of the polyelectrolytes, reducing the charge density and the amount of material to be deposited ${ }^{[18]}$. Moreover, the variation of $\mathrm{pH}$ can impact also the polymer conformation as it is expected to affect the charge density. Consequently, as mentioned previously, the film thickness may increase either linearly or exponentially with the deposited layers depending on $\mathrm{pH}$ variations and salt concentration ${ }^{[17]}$.

Moreover, $\mathrm{LbL}$ technique is quite versatile as it allows to use these natural polyelectrolytes to module mesenchymal stem cells (MSCs) behaviour. For instance, the LbL self-assembly of collagen/heparin multilayers have been effectively built up on poly (1-lactic acid) (PLLA) films to assess the combined effect of heparin on type I collagen (Col I) hierarchical organization on MSCs response. The presence of different Hep/Col I bilayers deposited electrostatically on polymeric substrates provides an osteoinductive and osteoconductive environment for MSCs at long term by promoting cellular differentiation and bone formation ${ }^{[27,29]}$. Similarly, the effect of LbL coating of Col I and hyaluronic acid as natural polyelctrolytes onto PLLA films on bone cells was evaluated. The presence of Col I as terminating layer proved an ehanced cytocompatibility of the PLLA films, improving the cell affinity and proliferation, directing the osteoblast organisation by contact guidance with the aligned fibril network ${ }^{[30]}$. Another study on the effect of LbL assembly of different combinations of natural polyelectrolytes on MSCs behaviour was recently published. This study found that surface topography, specifically a honeycomb-like porous structure as well 
as assembled bioactive molecules play significant roles on the adhesion and proliferation of MSCs ${ }^{[21]}$. Also, the nature of the assembled molecules affects significantly the spatial distribution of cells; particularly, the presence of GEL facilitated the cells to remain on the substrate surface rather than being confined within the pores.

In order to mimic the in vivo physiological microenvironment, scientists are also assessing the use of the LbL self-assembly method on functionalizing 3D porous scaffold surfaces. He et al, produced a silk fibroin scaffold by freeze-drying technique, and subsequently functionalized it through the deposition of cellulose nanowhiskers and chitosan multilayers. The final construct, based on a total of 108 self-assembled layers (Figure 3), exhibited improved mechanical properties, enhanced osteoblast proliferation and higher levels of biomineralization-relevant alkaline phosphatase activity in comparison to the untreated porous scaffolds ${ }^{[31]}$. Moreover, the polyelectrolytes combination based on chitosan/gelatin has lately been investigated to further regulate the cell attachment and proliferation of a hydrogel-based scaffold. The alginate-derived scaffold was fabricated via internal gelation and subsequently functionalized via immersive LbL electrostatic assembly. The resulting composite scaffold showed a better $3 \mathrm{D}$ architecture, along with improved mechanical properties and enhanced ability of attachment, proliferation and differentiation of osteoblastic MC3T3-E1 cells ${ }^{[32]}$. Furthermore, the use of natural polymers, as multilayer films, has also been greatly investigated for the coating of metal and metal-alloy bone implants to improve their bioinert behaviour. Recently, Wang et al investigated the effect of alginate/chitosan LbL coating on titanium substrates via electrodeposition. In this case, the applied voltage, the deposition time, and the concentration of the polyelectrolytes greatly influenced the thickness of the deposited layers. Moreover, the in vitro cytocompatibility tests exhibited good cell viability and proliferation, with a better cell morphology when the alginate was the outermost layer ${ }^{[33]}$. Beyond the use of natural polymers and since their first introduction in 2002, synthetic polycations (such as poly(ethylene imine) (PEI), poly(allylamine hydrochloride) (PAH), and poly(L-lysine) (PLL), and polyanions, including poly(sodium 4-styrenesulfonate) (PSS) and poly(L-glutamic acid) (PGMA)) are still widely used in pairs or combination with natural macromolecules for the production of multilayer films to modify the surface of bone tissue engineered structures ${ }^{[11]}$. Between the advantages of using synthetic polyelectrolytes, their chemical stability favors the stability of the topographical cues within the nanostructured coating ${ }^{[34]}$. The biocompatible properties of PSS in combination with chitosan as multilayers was been found to improve the biocompatibility of titanium thin films. The multilayer-based structures were stable when immerse for more than 3 week in Phosphate Buffered Saline (PBS), and the in vitro tests demonstrated a superior osteoblast adhesion and proliferation on the PSS/CHI coated films in comparison to the untreated substrates used as control ${ }^{[35]}$. Similar results were evidenced when applying the same combination of polyelectrolytes (CHI/PSS) on a polymeric substrate. Particularly, the proliferation and differentiation of osteoblast cells was greater on LbL-modified poly-DL-lactic acid (PDLLA) films rather than the native substrates ${ }^{[36]}$.

Additionally, the combination of electrostatically assembled biodegradable synthetic LbL coatings were investigated on AZ31 magnesium alloys. These coatings provided enhanced biocompatibility, adhesion and proliferation of both pre-osteoblast MC3T3 cells and hMSCs, 
in comparison to the uncoated alloy. The development of such surface treatment could be used to improve cellular integration for this kind of implants with the native bone tissue ${ }^{[37]}$. More recently, the osteointegration-derived ability of the well-established PSS/PAH multilayer has been further assessed using an osteoporotic rabbit model. The in vivo outcomes showed that bio-active PEEK with 20 PAH/PSS multilayers significantly improved bone mineralization in comparison to the untreated PEEK at the interface bone-implant as well as within the surrounding tissue. Similarly, no significant difference on microstructure property with respect to the native PEEK was reported by increasing the number of nanolayers from 5 to 10 . However, as the number of layers increased from 10 to 20 , island-like clusters appeared on the surface (Figure 4), followed by a markedly superior proliferation rate of bone marrow stromal cells (BMSCs). These results supported the hypothesis for which surface topography plays a pivotal role in regulating bio-function of $\mathrm{BMSCs}^{[38]}$.

\section{Influence of biomolecules release from LbL nanocoating}

It is well established that the surface-biological environment interactions are essential to drive the material performances in vitro and in vivo ${ }^{[39]}{ }^{[40]}{ }^{[41]}$. LbL allows to combine 3D complex substrates, mimicking the biological organ architectures, with a nanostructured multilayer functionalised with molecules or fillers to impart bioactive cues to the final device ${ }^{[7]}$. Following the LbL approach, scaffold bulk materials and structures can be engineered independently from the surfaces as it can be properly design to steer the cell response towards wanted behaviour ${ }^{[42]}$. In this section, the influence of different biomolecules both organic (e.g. growth factors, peptide sequences, drugs, etc.) and inorganic (e.g. hydroxyapatite, piezoelectric nanoparticles) from the multilayered LbL coating for bone tissue is summarized, in order to give an overview on the materials, procedures and most important findings within the last 5 years.

\subsection{Incorporation of organic biomolecules}

Bone morphogenetic proteins (BMPs), especially BMP-2 and BMP-7, have been extensively investigated for bone healing to enhance tissue regeneration as BMPs are key growth factors involved in bone regrowth inducing differentiation of progenitor cells to osteoblasts or bone cells ${ }^{[43]}$. LbL has been recognized as a powerful method to achieve therapeutic efficacy and safety of BMP functionalized surfaces as the multilayered structure ensures the maintenance of protein stability and prolongs its retention time at the site of action ${ }^{[44]}$. Microgram-scale loading of BMP-2 was successfully achieved functionalizing a polycaprolactone/ $\beta$-tricalcium phosphate (PCL/BTCP) 3D-printed scaffold by alternative dipping in chondroitin-sulphate and BMP-2 solutions respectively ${ }^{[45]}$. The multilayered architectures hindered the BMP-2 burst release (less than $1 \%$ after $3 \mathrm{~h}$ ) and guaranteed a prolonged release reaching a total cumulative release of 10 grams after 2 weeks that induced MC3T3 E1S4 pre-osteoblasts differentiation in bone cells.

Recently, unconventional polyelectrolytes able to enhance the protein stability within the multilayers have been proposed. The effectiveness of BMP-2 combined with graphene oxide has been evaluated by La et al. ${ }^{[46]}$. Graphene oxide $(\mathrm{GO})$ has emerged as an effective carrier for therapeutic proteins delivery, since its hydrophobic domains in the core region and ionized groups around the GO edges enhances GO hydrophobic and electrostatic interactions with 
proteins without affecting protein bioactivity. This feature makes this material a good $\mathrm{COO}^{-}$) graphene oxides, and further doping and proteins adsorption. BMP-2 adsorbed into GO-based nanomaterials demonstrated an improved osteointegration in titanium implants. In the attempt to mimic the physiological multi-cues environment, dual and multiple release of proteins have been investigated by combining BMP-2 with vascular endothelial growth factor ${ }^{[47]}$ or platelet-derived growth factor-BB ${ }^{[48]}$ in order to induce a simultaneous bone tissue growth and angiogenesis. The release of multiple growth factors evidenced that a more mature new bone was formed when compared to the single growth factor release ${ }^{[47]}$. Particularly, an increase of the local vascular network combined with a osteoinductive environment enhanced the bone remodeling at the injured site ${ }^{[48]}$.

Major challenges in the development of multicues nanolayers are the maintenance of protein stability, which could be affected by the process steps and the limited number of encapsulated proteins due to molecule size. Moreover, several problems are related with the use of proteins, such as: dose, cost, folding randomly, vulnerability to degradation, purification and immunogenicity ${ }^{[49]}$. To overcome these issues, the use of short peptides is a feasible approach to replicate the binding domains and signaling of the long chain proteins. Recently, Gentile et $a l$. proposed the nanoencapsulation of peptides within a multilayered LbL coating. Three peptides, KRSR (lysine-arginine-serine-arginine), NSPVNSKIPKACCVPTELSAI and FHRRIKA (phenylalanine-histidinearginine-arginine-isoleucine-lysine-alanine), were covalently bounded to PAH and then alternated to anionic PSS polyelectrolyte to coat composite poly(lactic-co-glycolic acid) (PLGA) /nano-hydroxyapatite electrospun membranes. In this work, three bone peptide sequences have been selected for improving specific stages in bone regeneration. From literature KRSR sequence, identified in different adhesive proteins related with bone (i.e. fibronectin, vitronectin, bone sialoprotein) was found to be suitable for enhancing the osteoblast adhesion to scaffold surfaces ${ }^{[50]}$; NSPVNSKIPKACCVPTELSAI, derived from BMP2, showed their potential to induce osteogenesis in vivo ${ }^{[51]}$, while FHRRIKA sequence, derived from bone sialoprotein, supported the matrix mineralisation ${ }^{[52]}$. An optimal peptide gradient was designed to induce a osteoinductive in vivo response after four-week implantation in non-healing rat calvarial defect model ${ }^{[33]}$. On this regard, the multicues nanolayers were designed to avoid random interactions with proteins by introducing targeted peptide-polymer conjugates ${ }^{[54]}$.

Different strategies can be used to regulate cell behaviour. For instance, poly(acrylic acid) (PAA) was functionalized with alendronate, a bisphosphonate targeting moiety with high affinity to bone, to be used as polyanionic compound to coat a solid substrate by electrostatically assembly with polycationic PLL (Figure 5) ${ }^{[55]}$. Moreover, RNA interference (RNAi) has been emerged as a powerful method to alter biological process by silencing targeted mRNA molecules. Small interfering RNAs (siRNAs) have demonstrated enormous potential as therapeutic agents in the treatment of several bone disorders, such as osteoporosis and cancer bone metastases and to enhance osteoblastogenesis ${ }^{[56]}$. Although many studies reported the effectiveness of the siRNA in steering biological events, the delivery of siRNAs in living systems still remains a challenge. Liposomes and polymeric nanoparticles are the main carriers used for siRNA, however LbL holds several advantages both in the processing steps (mild conditions, wide range of 
materials) and in the tuning of release kinetics. Furthermore, LbL technologies are based on easily triggered by using mild conditions $\left(\mathrm{pH}\right.$, temperature ${ }^{[57]}$. LbL based siRNA carriers have been reported, both for systemic and local delivery ${ }^{[58]}$. While systemic delivery is a versatile and challenging issue, the local delivery approach is easily applied, reduces unwanted side effects attributed to systemic delivery and ensures a sustained delivery of siRNA to the target tissue ${ }^{[59]}$.

The osteointegration of titanium surface is a highly investigated topic in orthopaedics and dentistry since implant failures are mainly associated to low integration between the implant surface and the surrounding bone. LbL was proposed to build up a nanostructured multilayers by loading an osteogenic siRNA that targets casein kinase-2 interacting protein-1 (siCkip-1)

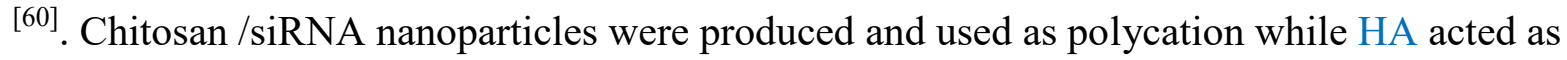
polyanion. A homogeneous multilayered structure was obtained on titanium surfaces when 8 bilayers were formed, providing a sustained release of siRNA over approximately one week. The effectiveness of the released siRNA was confirmed by the osteogenic differentiation of human osteoblast-like cells (MG63).

Recently, small non-coding RNA (MicroRNAs-miRNAs) have been investigated for their ability to coordinate a broad range of biological process. Indeed, miRNAs regulate developmental osteogenic signaling pathways, bone homeostasis, bone cells growth and differentiation and bone resorption mediated by osteoclast activity in adults playing an important role in tissue regeneration and bone disease treatment ${ }^{[61]}$. Few studies have indicated self-assembly technologies as a tool to enhance transfection efficiency and stability of miRNAs as naked miRNAs are rapidly degraded in vivo and they are negatively charged hindering their uptake by cell membrane (negatively charged) ${ }^{[62]}$. Recently, osteogenic BMSCs differentiation was regulated by targeting mRNA expression through the delivery of miRNA (miR-5106) loaded into nanoparticles. MiRNA loading efficacy and delivery kinetics was modulated by LbL-based approach, where PEI and liposomes (Lipo) were used as polyelectrolytes to coat gold nanoparticles (Au/PEI/Lipo) ${ }^{[63]}$. Optimized Au/PEI/Lipo-miR5106 nanocomplexes upregulated the expression of osteoblast genes enhancing the BMSC differentiation into osteoblast-like cells.

Alternatively to miRNA and siRNA, the delivery of gene encoding osteogenic proteins have been proposed to enhance the bone healing process ${ }^{[64]}$. Non-viral vectors can be obtained through layer by layer and the release kinetics can be optimized by modulating the number of layers and layers composition.

\subsection{Incorporation of inorganic biomolecules}

Many studies have shown the importance of organic-inorganic biocomposites on the performance of bone tissue engineering due to their biomimetic composition, which recapitulates physiological bone composition of collagen fibres and hydroxyapatite (HAP) crystals ${ }^{[65]}$ (Figure 6A). A mussel-inspired LbL assembly was developed by alternatively soaking titanium foil into dopamine buffer solution $(\mathrm{pH} 8.5)$ and the $1.5 \mathrm{X}$ simulated body fluid (SBF) solution ${ }^{[66]}$. Dopamine is a mussel derived molecule with highly adhesive property, which forms a polydopamine layer (PDPOA) in slightly alkaline environments ${ }^{[67]}$. Then, the surface was immersed into SBF solution to achieve HAP precipitation. Murine 
osteoblastic cell line MC-3T3-E was cultured on 9 bilayer- coated titanium surfaces showing good biocompatibility and high cell adherence ${ }^{[68]}$.

Another procedure for depositing HAP via LbL has been proposed by Manoukian et al. who developed a micro-nanostructured scaffold characterized by a spiral-shaped PLGA porous microstructure and a nano-HAP polyelectrolyte-based coating (Figure 6B). Nano-HAP was deposited through a LbL process with alternate deposition of cationic chitosan and anionic nano-HAP ${ }^{[68]}$. Unlike traditional HAP coatings, LbL increased the hydroxyapatite incorporation creating a highly porous multilayer for calcium and phosphate ions release, a fundamental step in reprecipitation of HAP crystals which leads to biomineralization in vivo. Indeed, it has been reported that excellent osteoinduction can be achieved when a $45-70 \mu \mathrm{M}$ calcium $/ \mathrm{mm}^{2}$ are released ${ }^{[69]}$. In order to achieve this therapeutic range, Manoukian et al designed a five chitosan/nano-HAP bilayers deposited onto the spiral structure. These multilayered structure released approximately $60 \mu \mathrm{M}$ calcium $/ \mathrm{mm}^{2}$ that resulted in adhesion, proliferation, and osteogenic differentiation of rat bone marrow stromal cells (MSCs). Then, scaffold was implanted for ten weeks into a rabbit ulnar bone defect model and in vivo tests reported a good bone regeneration, highlighted by the formation of new bone in the central section of the scaffold.

Although the many efforts to impart osteoinductive properties to the scaffold surfaces, one of the main causes of implant failure and low bone tissue regrowth is associated to infections. LbL offers the opportunity to add antibacterial properties to devices or scaffolds before implantation to reduce the risk of infection even in the long-term, as the antibacterial effect can be modulated to last after few weeks. Antibacterial composite coatings have been assembled using silver nanoparticles as antibacterial agent which, provide antibacterial properties by avoiding toxicity to human cells ${ }^{[70]}$.

Chitosan-silver nitrate complex and heparin were used as polyelectrolytes to produce an antibacterial coating on aminolyzed poly(ethylene terephthalate) (PET) and then, ascorbic acid were used to reduce silver ions forming silver nanoparticles (NP) ${ }^{[71]}$. Fourteen-layer chitosan-Ag NP/heparin multilayer films demonstrated antibacterial features on Escherichia coli BL21 strain as the number of bacteria was reduced of $90 \%$ after 5 hours, while no cytotoxic effect was detected using mouse MC3T3 osteoblast-like cells.

Recent findings have raised the use of inorganic nanoparticles to impart additional features to modulate cell fate ${ }^{[72]}$. Among others, antioxidant and piezoelectric particles have gained interest in the biomedical field for their ability to foster specific cellular behaviour ${ }^{[73]}$. Antioxidant multilayered surfaces have been recently studied for the first time in biomedical applications using quercetin as oxidant scavenger ${ }^{[74]}$. Inorganic nanoparticles based on redoxreactive metal oxides are an emerging as alternatives to traditional antioxidant agents like polyphenols, because inorganic nanoparticles present higher stability in physiological environment and longer half-life. In this context, the radical-scavenging role of ceria nanoparticles (nanoceria) has been established ${ }^{[75]}$ and LbL assembly has been applied for the development of sensors for dopamine detection ${ }^{[76]}$. Nanoceria nanoparticles were coated with polyacrylic-acid (polyacrylic-acid-coated nano-ceria, PNC) and then, multilayers were obtained alternating PNC with poly(diallyldimethylammonium chloride) (PDDA). Finally, piezoelectric nanoparticles have gained increasing interest as the human bone tissue is also a type of piezoelectric material. Many studies have reported the ability of piezoelectric 
materials to promote bone growth ${ }^{[77]}$. To date the application of multilayered piezoelectric surfaces in the biomedical field has not been reported yet. However, the feasibility of the method has been demonstrated by assembling piezoelectric $\mathrm{BaTiO}_{3}$ (BTO) coated with oleic acid (OA) and PAA ${ }^{[78]}$, that opens the opportunity to investigate deeply the use of piezoelectric materials as polyelectrolyte for the formation of a functional multilayer. Table 1 summarizes the current use of LbL technologies to add functional moieties to nanostructured coatings.

\section{Visionary perspective applications of LbL technology}

In this final section, vision opportunities on different $\mathrm{LbL}$ technologies are discussed to envisage new frontiers and challenges for the scientific community. Particularly, this section describes new LbL strategies for the manufacturing of efficient LbL-coated nanoparticles for the treatment of bone cancer, LbL-coated in vitro bone model and LbL-coated films as bienzyme sensors for diagnostic and monitoring applications respectively (Figure 7).

\subsection{Spray LbL assembly for the manufacturing of nanoparticles as active defense system for treatment of bone cancer}

Bone is the most preferred organ for the formation of metastatic cancer because of its microenvironment. Furthermore, cancers, particularly in prostate, breast, kidney and lung, have a possible opportunity to be transferred to bone ${ }^{[79]}$. Currently bone tumor treatments mostly include surgical removal of detectable disease followed with chemo- and radiotherapies ${ }^{[80]}$. However, surgery operations are generally difficult to remove completely the bone-tumor cells and remaining tumor cells are present around the bone. Moreover, conventional radio- and chemo- therapies has been largely used in order to eliminate definitely these residual tumor cells, but the related side-effects of these treatments provide acute suffering to patients ${ }^{[80,81]}$. So far, the important challenge of eliminating residual tumor cells as well as repairing bone defects produced by the removal of the malignant bone tumor is still open ${ }^{[82]}$. Thus, it is of unlimited importance to design and manufacture smart biomaterials able to kill the remaining bone-tumor cells by using an efficient and secure protocol, and, at the same time, to harness the biomaterials bioactivity for improving the healing of the bone defect after surgical bone tumor removal. In the last 5 years, an extraordinary growth has been noticed in nanomedicine on the production of innovative nanoparticles for the diagnosis and treatment of cancer disease. Nanoparticles possess suitable biological properties due to their large surface area/volume ratio and small size, enabling to absorb, bind and transport several types of substances, ie. drugs, proteins, DNA, RNA, etc. with great efficiency ${ }^{[83]}$. Therefore, their properties allow them to have great stability, carrier ability, ability to embed both hydrophobic and hydrophilic compounds, making them extremely promising in many features of oncological field ${ }^{[81,83,84]}$. In our opinion, LbL assembly can be an extremely useful add-value in order to quickly manufacture multifunctional NPs in a made-to-order approach ${ }^{[85]}$, allowing as an alternative translation approach that can be exploited in industry. Up to date, the main importance has been on the use of the LbL coatings as non-degradable membranes for specific deliver of biomolecules present in the core, and no attempts have been reported to obtain the ability to target tumors within the film structure ${ }^{[86]}$. NPs have the tendency to accumulate passively in the interstitials of the tumor after long circulating, and there is an increasing evidence that the incorporation 
of targeting moieties enhances the uptake of NP by cancer cells and extends their permanence

time into the tumor ${ }^{[87]}$. An interesting approach can be to impart these biological capabilities to LbL-coated nanoparticles towards clinical use. The conventional and common strategy to achieve tumor selectivity is to coat the nanoparticle surfaces with ligands that can target specifically cancer cells ${ }^{[88]}$. However, this biofunctionalization strategy is limited to "mild"based chemistry. Therefore, a pH-based approach for cancer targeting can be based on the exploitment of the acid $\mathrm{pH}$ extracellular micro-environment of tumor colonized bone, that approximately is within the range 6.5-7.0 ${ }^{[89]}$. This $\mathrm{pH}$ shift can trigger the LbL multilayer disassembly with consequent biomolecules/drugs deliver or to provide and activate specific cell-targeting ligands that are not accessible under neutral environments within the multilayers ${ }^{[90]}$. A pioneering work on this topic has been reported by Poon et al ${ }^{[91]}$ where, in order to prove a method for achieving the selectivity of tumor cell via LbL coating degradation, they manufactured nanoparticles coated, via dipping LbL-assembly, with trilayers of poly-L-lysine modified with iminobiotin, followed by the linker protein neutravidin and biotin end-functionalised poly(ethylene glycol) (PEG). Their main aim was the in vivo targeting of tumor hypoxia. Each materials of the nanocoating was selected following a specific rationale: (1) PLL for improving NPs cellular uptake; (2) the affinity between iminobiotin and neutravidin is $\mathrm{pH}$-dependent that means stable within the $\mathrm{pH}$ range 8-12 but quickly degraded within the $\mathrm{pH}$ range $4-6$ due to a less interaction of the protonated iminobiotin with the neutravidin ${ }^{[92]}$; finally (3) PEG as antifouling material that allows the coated NPs to avoid fast reticuloendothelial system clearance ${ }^{[93]}$, for improving their accumulation in the interstitials of the tumors thanks to enhanced permeation and retention effect ${ }^{[94]}$. The authors demonstrated that this approach may be possibly used to target all types of cancer, as well as those that do not express distinct markers at the surface. Different polyelectrolytes have been recently investigated, with a more extended stability at neutral physiological $\mathrm{pH}$. Indeed Laing et al. designed and manufactured nanoengineered multilayer capsules via dipping-LbL assembly, based on the charge-shifting polymer, poly(2diisopropylaminoethyl methacrylate) (PDPA), coupled chemically with lauryl methacrylate (C12) component. The obtained capsules showed to be stable at $\mathrm{pH} 7.4$, and were activated at narrow cellular $\mathrm{pH}$ shifts in order to quickly degrade at endosomal $\mathrm{pH}$, enabling to overcome the limitation of conjugating small biomolecules/therapeutics to the carrier (that implies chemical reaction) without compromising the properties of the biomolecules ${ }^{[95]}$. Furthermore, these capsules showed a controlled release of different hydrophilic molecules with a wide molecular weight range (from 500 to $70 \mathrm{kDa}$ ).

Another consideration for the obtainment of active and efficient defense system for bone cancer treatment should be done. To the best of our knowledge, up to now few biomaterials have been proposed with a double function of tumor therapy and tissue regeneration applications respectively. Recently, photothermal therapy (PTT), that consists in a minimally invasive and very efficient anticancer treatment, showed to improve efficacy of tumor therapeutics and avoid side effects in several in vivo animal tests ${ }^{[96]}$. PTT is based on specific photo-thermal agents that transform near infrared (NIR) light/irradiation into heat and ablate tumor by hyperthermia ${ }^{[97]}$. Thus, the scientific community may be involved in researches for the fabrication of novel bi-functional biomaterials with photothermal therapeutic ability in order to treat tumor cells and to repair bone defects derived from surgical resection. In this 
direction, Cheng et al. ${ }^{[98]}$ proposed a novel PTT system based on poly $(3,4$ ethylenedioxythiophene) and poly(4-styrenesulfonate) (PEDOT:PSS), both used as polymeric combination in organic electronics field ${ }^{[99]}$ and evidences high absorbance in the nearinfrared region, for extremely in vivo photothermal ablation of tumors in mice. In this work, negative-charged PEDOT:PSS nanoparticles were firstly functionalised with positive-charged PAH and, after, negative-charge PAA. After the crosslinking of the two layers with the amides formation, a branched PEG was conjugated onto the surface of these nanoparticles, for improving their stability under physiological conditions ${ }^{[100]}$. The obtained functionalised nanoparticles showed a "stealth-like" behaviour, characterized by an extremely high tumor accumulation because of the cancerous EPR effect.

Therefore, the strategy to incorporate efficient PTT systems in 3D porous scaffolds has to be pursued as reported by Wang et al. ${ }^{[101]}$. In their work they incorporated molybdenum-based $\left(\mathrm{MoS}_{2}\right)$ nanosheets on the surface of ceramic 3D printed scaffolds, as highly PTT potential. They showed that, under NIR, the scaffold temperature quickly increased and efficiently controlled by modifying the content of $\mathrm{MoS}_{2}$ nanosheets, as well as scaffold dimensions and density of the laser power. Biological studies demonstrated the efficiency of photothermal temperature in vitro in decreasing breast cancer and osteosarcoma cells viability, and in vivo in the inhibition of the tumor growth. Moreover, the scaffolds allowed the adhesion, proliferation and osteogenic MSCs differentiation, inducing in vivo bone regeneration. This bi-functional scaffold, able to treat the bone cancer and support the growth of bone, offered an encouraging clinical approach for the treatment of bone defects induced by tumor. This proof of concept work demonstrated the practicability of the combination of localized therapy for tumor with tissue regeneration by using multi-functional and multi-layered materials. Compared with the physical absorption of photothermal therapeutics, as reported in the Wang's research, LbL assembly can allow to improve the efficiency and the release time rate of the therapeutic agents, reducing their content that may be dangerous for the overall cytocompatibility of the scaffolds.

Finally, the use of siRNAs is taking a great attention as targeted therapeutics with the capacity for the treatment of tumors that are unaffected by the conventional therapies ${ }^{[102]}$. Therefore, the combination of genetic targeting of specific resistance tumor cell pathways with the chemotherapy drugs release can offer the opportunity to 'switch' or 'turn off' the ability of tumor cell to fight, with a great efficacy increase of the treatment. But, to make significant clinical siRNA therapeutics for treating advanced pathologies, important features should be considered: (1) extended permanence of NPs in circulation to permit continuous therapy to the tumor cells ${ }^{[102]}$; (2) effective siRNA embedding into the nanoparticles to avoid losses from the low uptake and endosomal escape rates into tumor site ${ }^{[103]}$; (3) biomaterials should control the siRNA endosomal escape avoiding the cytotoxicity ${ }^{[104]}$. In literature recent works reported different biomaterials for the preparation of suitable siRNA-loaded nanoparticles, eg. block copolymers ${ }^{[105]}$, copolypeptides ${ }^{[106]}$, cyclodextrins, and charged-lipids, that can solidify at $37^{\circ} \mathrm{C}^{[107]}$. However, it is challenging to mediate or modify factors for siRNA release, eg. siRNA molecules embedded into the nanoparticles and the ratio between siRNA and cationic polymer/lipid that may influence dramatically the therapeutic window. Indeed, several lipoplex and polyplex systems are made of lipid or cationic polymer for the "package" incorporation of the siRNA, where the molar ratio between polycation and siRNA can achieve 
high values, from 10 to 20:1. These process parameters can increase toxic side effects with a

consequent decrease of the siRNA amount released systemically ${ }^{[108]}$. Finally, recent works revealed that several siRNA-complexes do not offer a synergic combination of chemotherapy drugs with inhibitors: this is a new open challenge that includes chemotherapy loading in a "modular fashion". Therefore, in our opinion LbL-coated nanoparticles can offer an exciting siRNA- delivery systems with interesting clinically translational potential. Few researchers have described the procedures to incorporate siRNA molecules into the superficial coated layers of nanoparticles ${ }^{[62,109]}$. Recently, Deng et al. reported a novel co-delivery system, to target a strong aggressive breast cancer form, made of multilayered coating on the chemotherapy drug-loaded NPs surface (via alternative deposition of siRNA and poly-Larginine as bilayer with the possibility to actually incorporate up to 3500 siRNA molecules), as shown in Figure 7, followed by additional functionalisation of an outer coating for tumortargeting and "stealth" properties ${ }^{[109]}$. Up to date, no studies on the effect of siRNA release from LbL-coated NPs on bone cancer are present in literature; thus it still remains an open challenge to be deeply investigated.

Finally, an ultimate consideration can be done on the manufacturing of the LbL-coated NPs that have been largely mentioned in the previous paragraphs. Although all these researches used the conventional dipping LbL assembly for the NPs manufacturing, the alternative spray LbL assembly can be strongly considered because it is much faster than immersive assembly, and the length of cycle for adsorption is reduced to a few seconds ( $\sim \mathrm{s}$ per layer) in comparison to the immersive coating that requires an average of 15 min per layer ${ }^{[110]}$. In addition, another important advantage of the spray-based system is related to the possibility of recycling the solution in the original reservoirs ${ }^{[111]}$. In the case of drug incorporation, the spray LbL enables the build-up of nanocoatings with a greater system efficiency, since it contributes to maximize the drug loading, preventing the diffusion within the dipping bath [112].

The ease of the spray-assembly method, combined with the rapid process times along with the increased efficiency observed offer great promise for the translation of this technology from the laboratory scale to industrial level mass production.

\subsection{Dipping LbL assembly for nanocoated cellular systems for cell-based therapy}

Cell encapsulation using the LbL deposition method implies the coating of a multilayered films on single cells or cell aggregates surfaces ${ }^{[113]}$ (Figure 7). This LbL strategy has impressive potentiality for proposing new solutions for bone regeneration. However, differently with the resilient and thick microbial cells lipid bilayer, cells from animals do not have the polysaccharide-reinforced cell wall that allows them to be disposed to mechanical stresses and osmotic pressure. Thus, a deep biomaterials selection for coating animal cells is essential ${ }^{[114]}$. Moreover, the cell surface exposure to a positive-charged layer may lead to the disruption of the cell membrane, causing apoptosis. However, due to the fact the cells are exposed minimally to the polycations toxicity and due to the high permeability of cell capsules, hydrogen bonding-based LbL coatings evidenced higher cell viability $(\sim 80 \%)$ when compared with the ionically-based layers $(<25 \%)^{[115]}$.

Multilayered coating of single cells has been used to define appropriate microenvironments to regulate cell behaviour (eg. adhesion, proliferation and differentiation) by, as example, the 
addition of osteoinductive biomolecules in the multilayer, such as specific growth factors, coating in order to be delivered according specific times and $\mathrm{pH}$, thus improving the regulation of MSCs [-differentiation in osteoblasts. The use of natural polymer-based polyelectrolytes (eg. gelatin, chitosan) are required in order to have a cytocompatible coating that not affect significantly the MSCs viability, as proposed for other applications involving neural stem cells ${ }^{[16]}$.

Another challenging target can be represented by LbL deposition of multilayers for coating transplanted allogenic cells, to avoid immune rejection. The reaction of immune system is a frequent problem for using biomaterials in order to regeneration all tissues. Particularly, cells transplantation, scaffolds implant, or biomolecules deliver can lead this immune response. Although the immune reaction realizes several necessary tasks, eg. removal of cellular debris due to injuries and reducing infection, the early inflammatory response can cause further damage to the tissue ${ }^{[117]}$, that can compromise the healing. Therefore, it is fundamental to not prevent completely the macrophages infiltration because it can stimulate more wide tissue damage combined with regeneration ability decrease ${ }^{[118]}$. Preliminary experiments have been performed on human cartilage cells encapsulation within LbL coating of sodium cellulose sulfate (as polyanion) and poly-diallyl(dimethyl-ammoniumchloride) (as polycation) where an efficient immunoprotection in vivo has been proved ${ }^{[119]}$.

\subsection{Fluidic LbL assembly for the obtainment of in vitro bone model}

Further application of LbL assembly can include the manufacturing of microfluidic devices, called organs-on-chips that have been designed and created to mimic tissues/organs in order to simulate the physiological cellular micro-environment. Recent findings on these microfluidic models have started to recreate in vitro pathological states in order to improve the knowledge on the biological processes as well as for drug screening. These microfluidic systems show great potential for pharmaceutical, biomedical and toxicological fields ${ }^{[120]}$. Moreover, in vitro models have the potential to offer an ethical approach with improved scientific accuracy that is more appropriate from both an animal welfare and scientific view. Recently researchers are concentrating their attention on the in vitro manufacturing of bone tissues for mimicking functional properties of natural bone, such as microarchitecture and mechanical strength. One of the big challenges is due to the fact that, although cancellous and cortical bone are structural different, they both include a vascularised network, fundamental to nutrient flow and waste removal. Thus, microvascular systems can be designed and manufactured as 3D in vitro models for evaluating biological processes in living systems. Particularly, up to date, microfluidic devices have been developed for vascularized bone tissue models to investigate breast cancer metastasis to the bone and cancer extravasation via simulating an osteo-cell condition micro-environment ${ }^{[121]}$. Moreover, platforms of vascularised in vitro bone model are under investigation in order to evaluate angiogenic potential ${ }^{[122]}$, as well as in combination of osteogenesis ${ }^{[123]}$, because bone angiogenesis has significant part in bone tissue formation and regeneration. However, these traditional or microfluidic in vitro models were not able to simulate the bone angiogenesis in vivo that is characterized by the growth of the vessels within the mineralised bone Extracellular Matrix $(\mathrm{ECM})^{[124]}$. Furthermore, a suitable platform for manufacturing in vitro bone tissue should 
possess 3D structures with interconnected pores as well as appropriate mechanical properties to support the cell activities, such as adhesion, proliferation, and differentiation. Thus, a further manufacturing approach can combine the layer-by-layer assembly deposition with the $3 \mathrm{D}$ printing in order to model vascularised bone for creating porous and channeled structures and biomolecules gradients.

As example, the biological environments able to support the viability and spreading of cells (osteoblasts and osteocytes) or to block their migration can be studied in terms of multilayered coating stiffness with or without the incorporation of specific short peptide sequences like RGD ligand. Moreover, the influence of VEFGs in combination with mono-, co-, and tri-cultures on the formation of capillary like network in 3D can be an surplus investigation in order to offer evidence on the influence of the different component on the angiogenesis ${ }^{[125]}$. Among all the different LbL technologies, the fluidic assembly has the suitable characteristics to coat, with or without biomolecules incorporation, channel walls and substrates placed or immobilized in a 3D printed microfluidic device. This LbL technology is usually applied by a capillary force, pump, or spinning in order to allow the liquid flow through the channels. Furthermore, in literature specific perfusion chambers are described for fluidic layering of complex 3D structures, ie. sensitive biological substrates, that can continue to be constantly hydrated during the coating ${ }^{[126]}$.

\subsection{Electromagnetic LbL assembly applied for bienzyme sensors}

Bone is a very dynamic tissue with the ability of constant remodeling all over adult life. Currently, the gold standard to evaluate bone remodeling and mineral density has defined limits, novel methods are being developed ${ }^{[127]}$. Enzyme-linked immunosorbent assays (ELISAs), that assess amounts on picogram scale, are usually used for measuring specific bone turnover markers (BTMs) ${ }^{[128]}$. Among others, two formation markers (serum bonespecific alkaline phosphatase (s-BALP) and serum procollagen type I N-terminal propeptide (s-PINP)) and two bone resorption markers (urine N-terminal telopeptide of type I collagen (u-NTX) and serum C-terminal telopeptide of type I collagen (s-ßCTX)) are the most commonly used in clinics to monitor osteoporosis ${ }^{[129]}$. This evaluation is of great significance for clinicians in order to monitor the fractured bone biomechanics and its remodeling process for selecting the suitable treatment to reduce complications and improve the quality of life of the patient ${ }^{[130]}$. However, these ELISA assays are very expensive in terms of high material costs, and require long period of incubation and particular equipment, which need clinical samples to be sent to a lab with growing costs and processing time due to the fluorescent labelling ${ }^{[130]}$. Another method for controlling the healing of bone fracture is based on difficult imaging technologies that not allow to observe the patient during outpatient visits or physiotherapy ${ }^{[131]}$. Therefore, due to the above mentioned limitations, there is an increasing request to manufacture different biosensors to offer low-cost miniaturized platforms to evaluate more precisely bone remodeling process.

In order to offer accurate, quick, easy, point-of-care assessment of biomarkers, electric fieldinduced LbL can be an interesting option for the manufacturing of biosensors for the detection of specific and sensitive biomarker detection. This specific LbL technology has already been explored in biomedical application for the preparation of biocompatible nanocoatings, which negligible cytotoxicity has been reported by Wang et al ${ }^{[33]}$ through in vitro biological tests. 
Particularly, in this work chitosan and alginate were used as polyelectrolytes to coat Ti-based substrates. During the electrodeposition process at constant voltage of $20 \mathrm{~V}$, the titanium plate was the anode to deposit the initial alginate-based layer combined with a parallel platinum plate as counterelectrode. After drying, a second chitosan-based layer was deposited but using the previous titanium plate as cathode and the parallel platinum plate as counterelectrode. This procedure was repeated several times in order to create a stable nanocoating. Compared with the traditional bienzyme assays, electromagnetic LbL gives the opportunity to prepare bienzyme coatings with bioelectric catalytic functions characterized by high surface coverage and, thus, activity, decreasing the correlated costs through the use of available commercial sensors, and may utilize easy assays that do not involve any labelling variation. A pioneering study on the use of electromagnetic LbL assembly for bienzyme sensors manufacturing is reported by Shi et al. ${ }^{[132]}$. They proposed a multilayered film based on enzyme and polyelectrolyte on a transparent indium-tin oxide covered glass electrode surface, where two different enzymes were distributed homogenously laterally on the same substrate without interfering. Particularly, electromagnetic LbL assembly was used to deposit alternatively different redox enzymes (glucose oxidase and catalase) and PDDA. The authors demonstrated that was the possibility to regulate correctly the enzyme activity and spatial arrangement, enabling to build multilayered bienzyme sensors as desired. Therefore, electromagnetic LbL assembly can open the field for a next generation of biomechanical multi-enzyme systems with strong evidenced on the quality of live bone.

\section{Conclusions}

As J Richardson et al said: "overall, the future of LbL assembly is bright, and as the black box of assembly technologies is slowly illuminated, great potential for innovation and application will be found" ${ }^{[7]}$. Layer-by-layer assembly is a consolidated technology and presents an unlimited potential to be used in diverse and multiple fields. Although several new approaches and developments have been proposed for the treatment of bone-related diseases and regeneration, unmet challenges are still present. Actually, there is a need for faster and more stable coatings to enable long term storage of multilayer systems and manufacturing of innovative and efficient bone medical devices at low costs and high reproducibility. On this regard, the combination of LbL method with nano-drug delivery technology can offer a fully integrated approach to treat other bone disorders, e.g. osteoporosis, osteomalacia, etc. LbL assembly-based methods, integrated with other fabrication technologies (e.g. additive manufacturing), can significantly lead to revolutionary and novel developments (unique multilayer properties or accelerated deposition processes) in order to overcome the remaining challenges of the industrial manufacturing scale-up. Finally, progresses in LbL technology is happening quicker than ever, mainly in biomedicine field, and it is expected that new LbL assembly-based methods subcategories will be complemented to increase past conventional, non-conventional and quasi-LbL assembly.

\section{Acknowledgement}

This work was supported by Newcastle University. Ana M. Ferreira and Piergiorgio Gentile are member of the UK EPSRC Centre for Innovative Manufacturing of Medical Devices (MeDe Innovation, EPSRC grant EP/K029592/1). Ana Marina Ferreira Duarte and Chiara Tonda-Turo contributed equally to this work. 


\section{Figures}

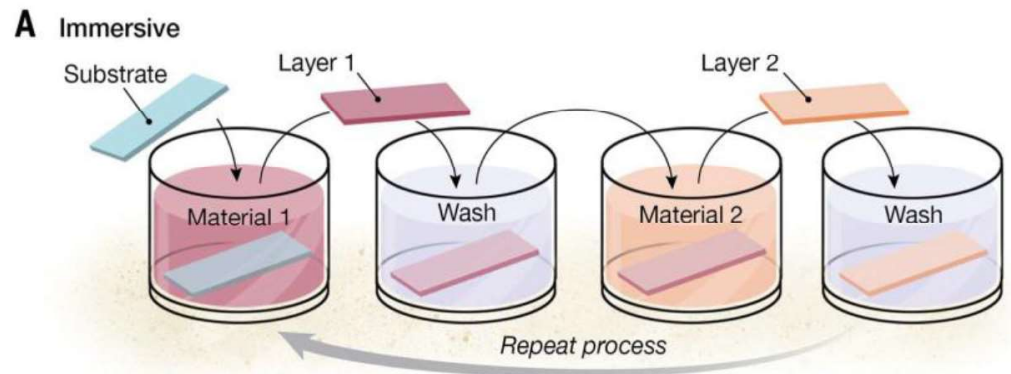

B Spin

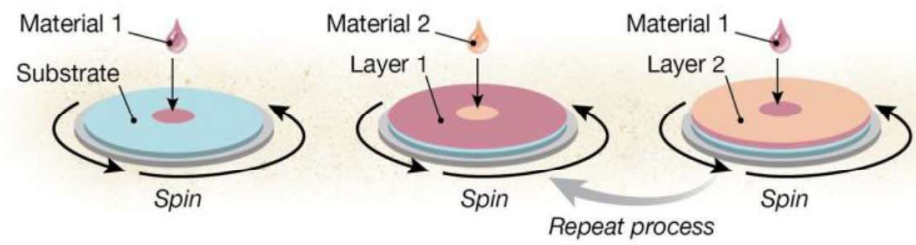

C Spray

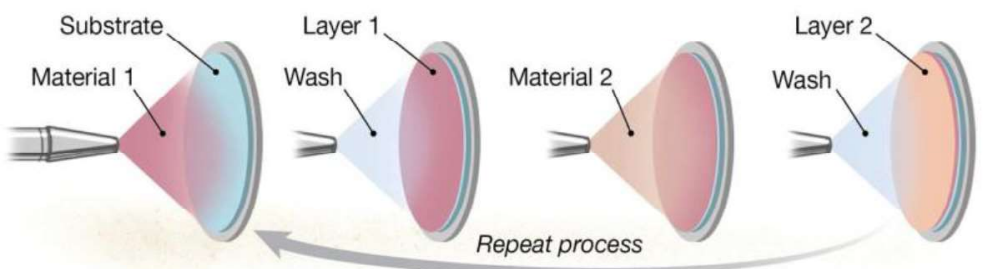

D Electromagnetic

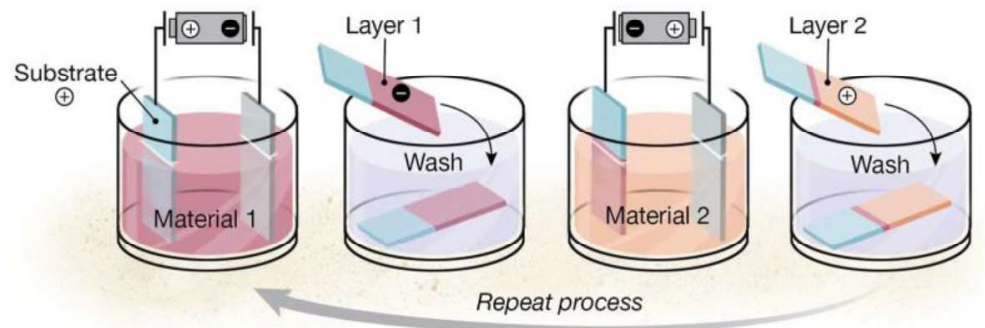

E Fluidic

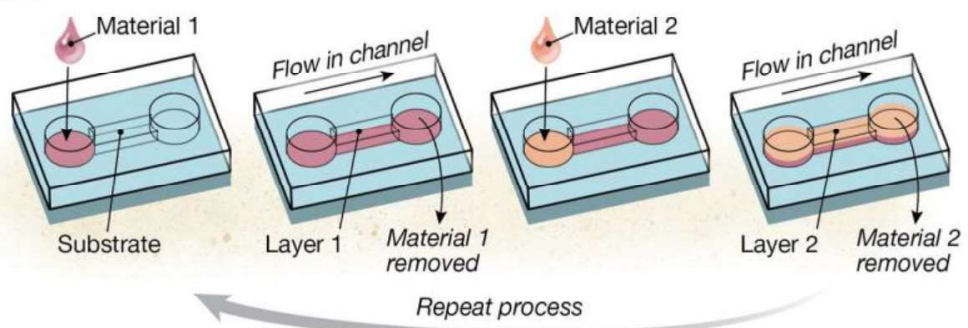

Figure 1. Layer-by-layer assembly technologies. (A to E) Schematics of the five major technology categories for LbL assembly. Reproduced with permission ${ }^{[7]} 2015$ The American Association for the Advancement of Science. 
Figure 2. Last five years of LbL assembly applied to bone tissue field: cumulative number of yearly publications for search topic keywords of "layer-by-layer bone", "layer-by-layer bone regeneration", "layer-by-layer bone nanoscale" or "layer-by-layer bone drug delivery" since 2014. This timeline is intended to highlight the general trends of LbL assembly in bone applications and is not exhaustive. Search performed in ISI Web of Knowledge database on July 11, 2018. 

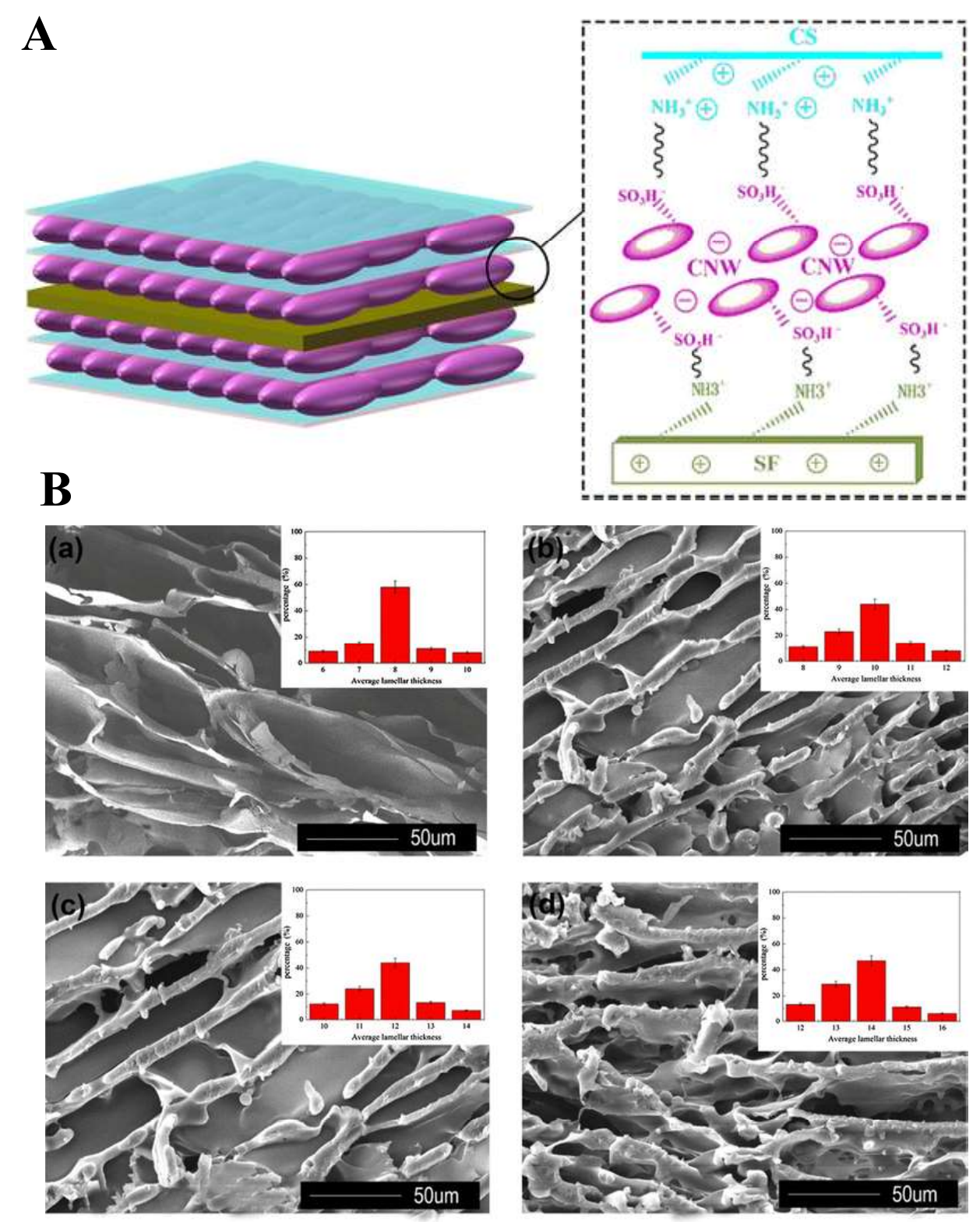

Figure 3. (A) Schematic diagram of layer-by-layer self-assembly of CNW and CS onto SF substrate. (B) SEM images of a pure SF scaffold and b, c, d SF/CNW-CS composite scaffold with 32, 54, 108 assemble layers, respectively. Reproduced with permission $^{[31]} 2016$, Springer. 


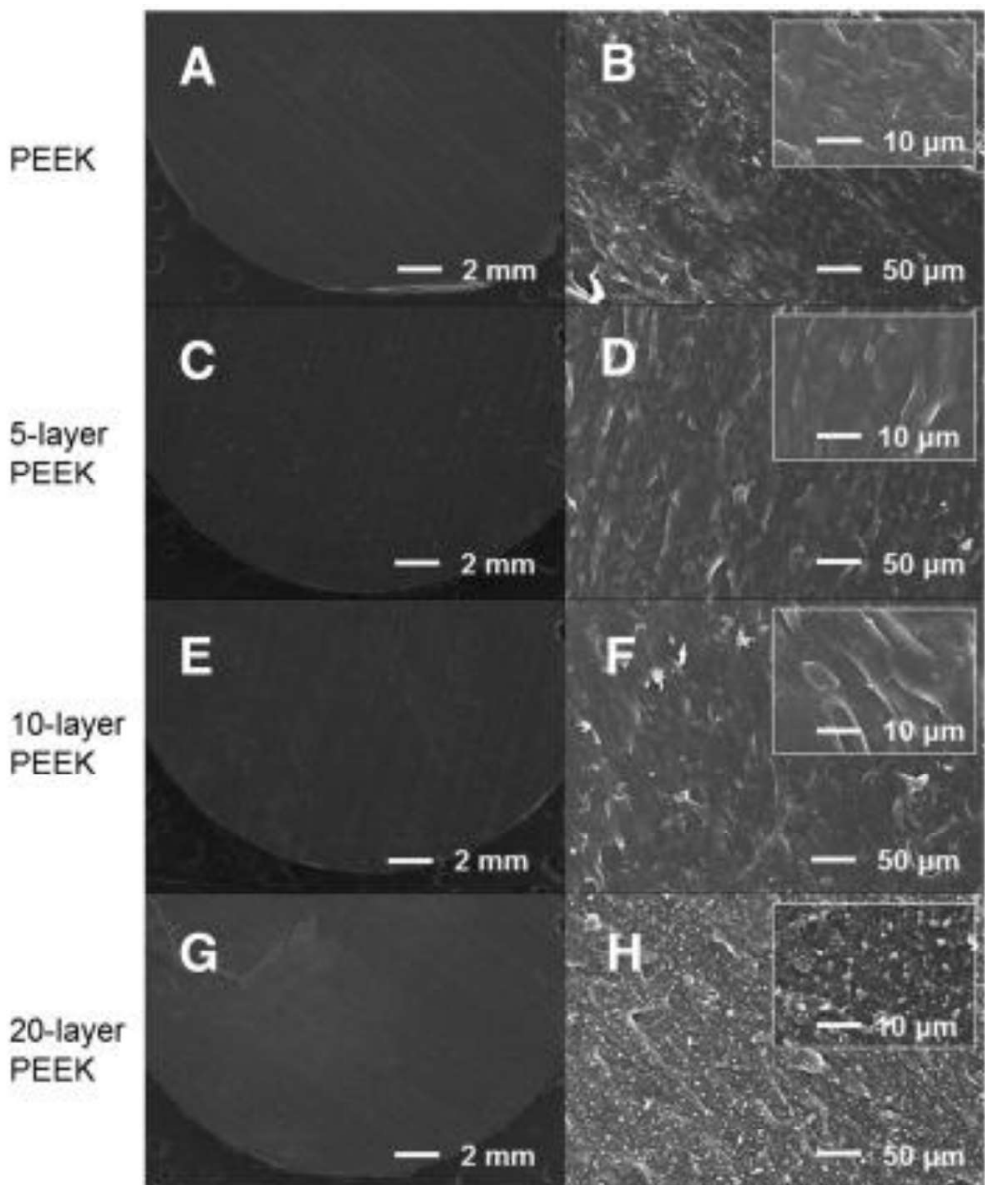

Figure 4. SEM micrographs of native PEEK (A, B), and LbL treated PEEK after 5 layers (C, D), 10 layers (E, F) and 20 layers (G, H). Reproduced with permission ${ }^{[38]}$ 2017, Elsevier.
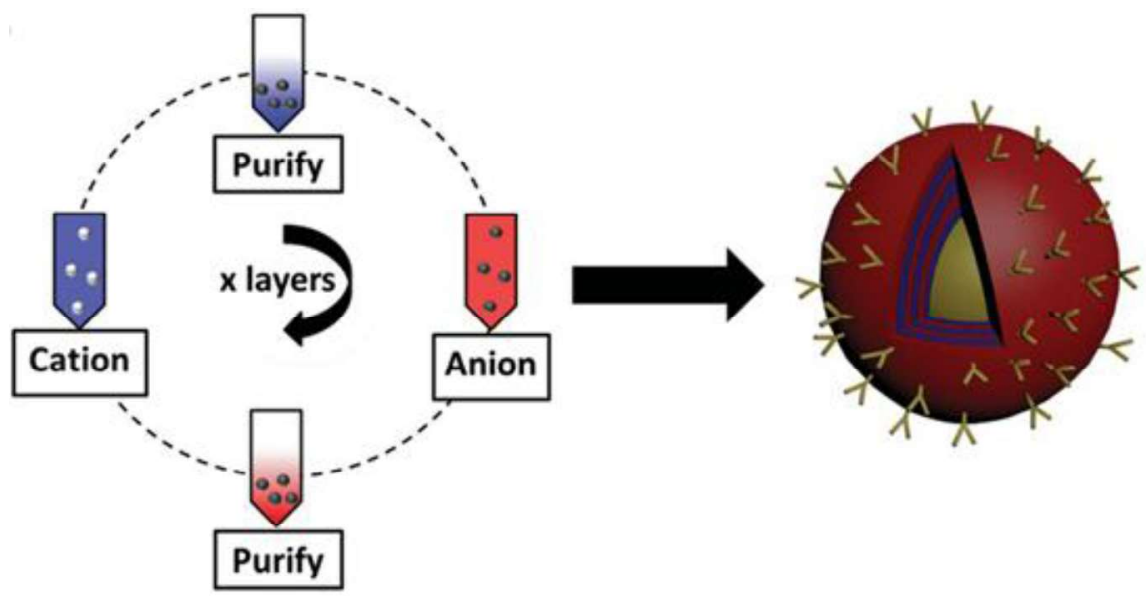

Figure 5. Process for LbL-coated nanoparticles (NPs). NPs were iteratively coated with anionic polyelectrolyte (PAA) and polycationic poly- L-lysine (PLL). PAA was functionalized with the bisphosphonate targeting moiety to boost the NPs affinity to bone cells. Reproduced with permission ${ }^{[55]} 2013$, Wiley-BCH. 
A

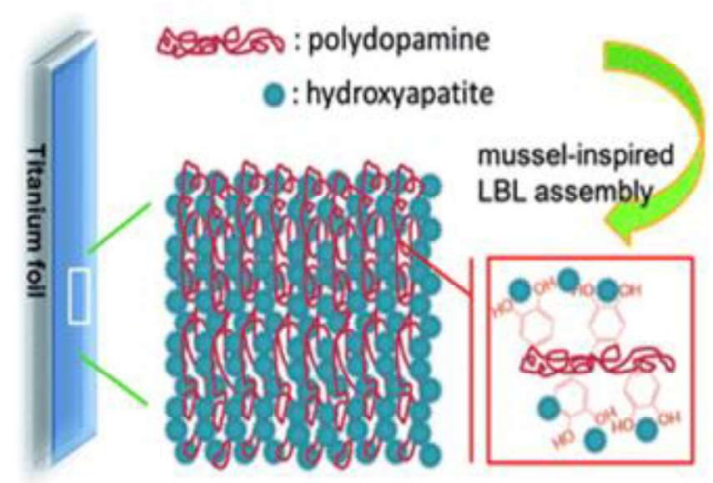

B

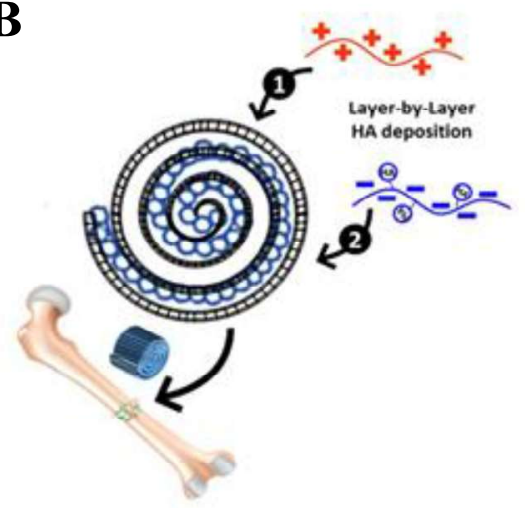

Figure 6. Schematic representation of two approaches to produce a biomimetic organicinorganic biocomposites through LbL methodology. (A) Composite multi-layered coating on Ti substrate obtained by alternative assembly of dopamine and HAP where a polydopamine layer (PDPOA) was obtained in slightly alkaline environment and then immersed into SBF solution to achieve HAP precipitation; the process was repeated nine times to obtain nine bilayers. (B) Spiral shaped PLGA-based construct coated with alternate layers of cationic chitosan (in red) and anionic HAP (in blue) to mimic both the composition and the structures of bone tissue. Adapted with permission from ${ }^{[6]} 2014$, RSC and from ${ }^{[68]} 2018$, ACS Publications. 


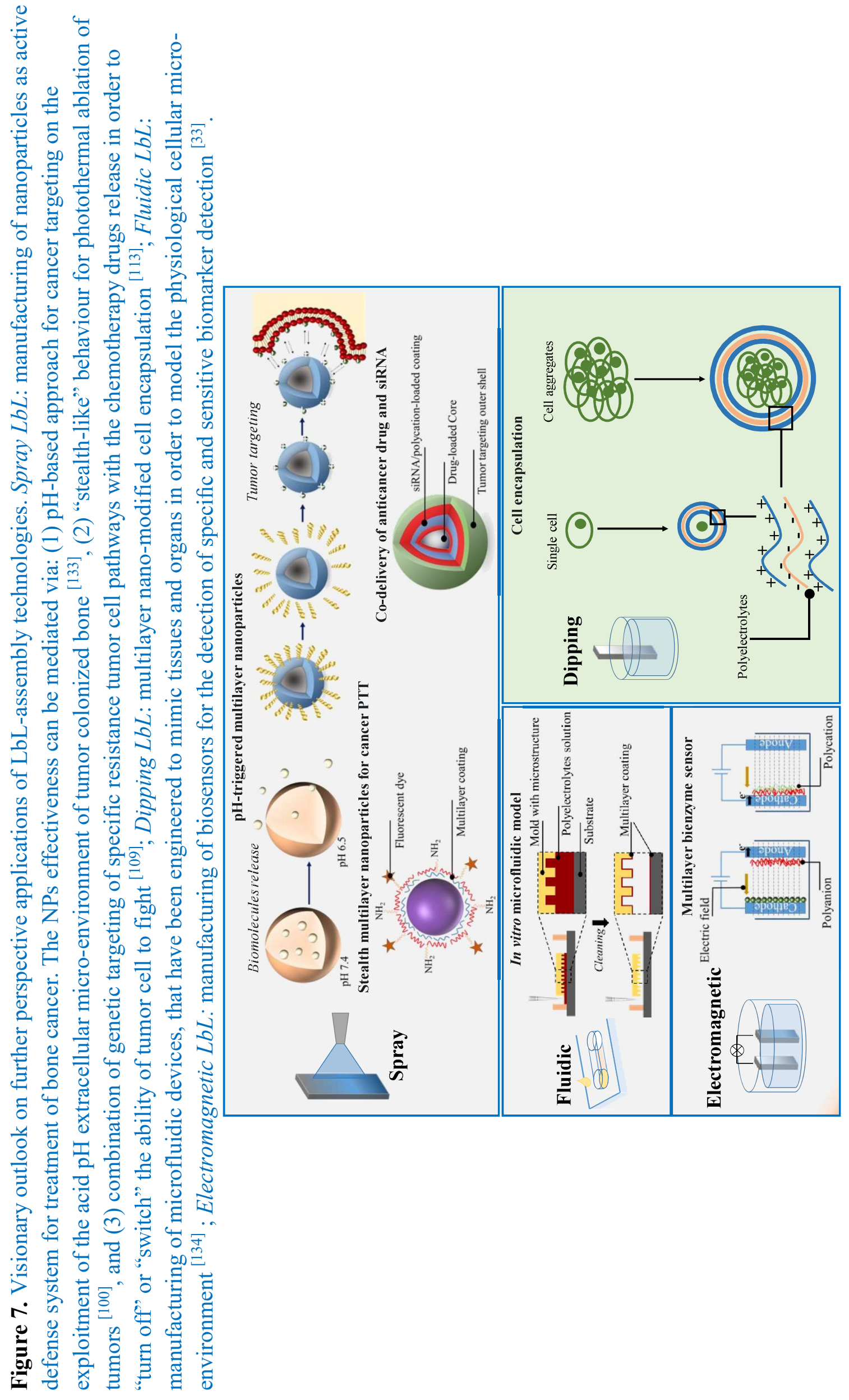




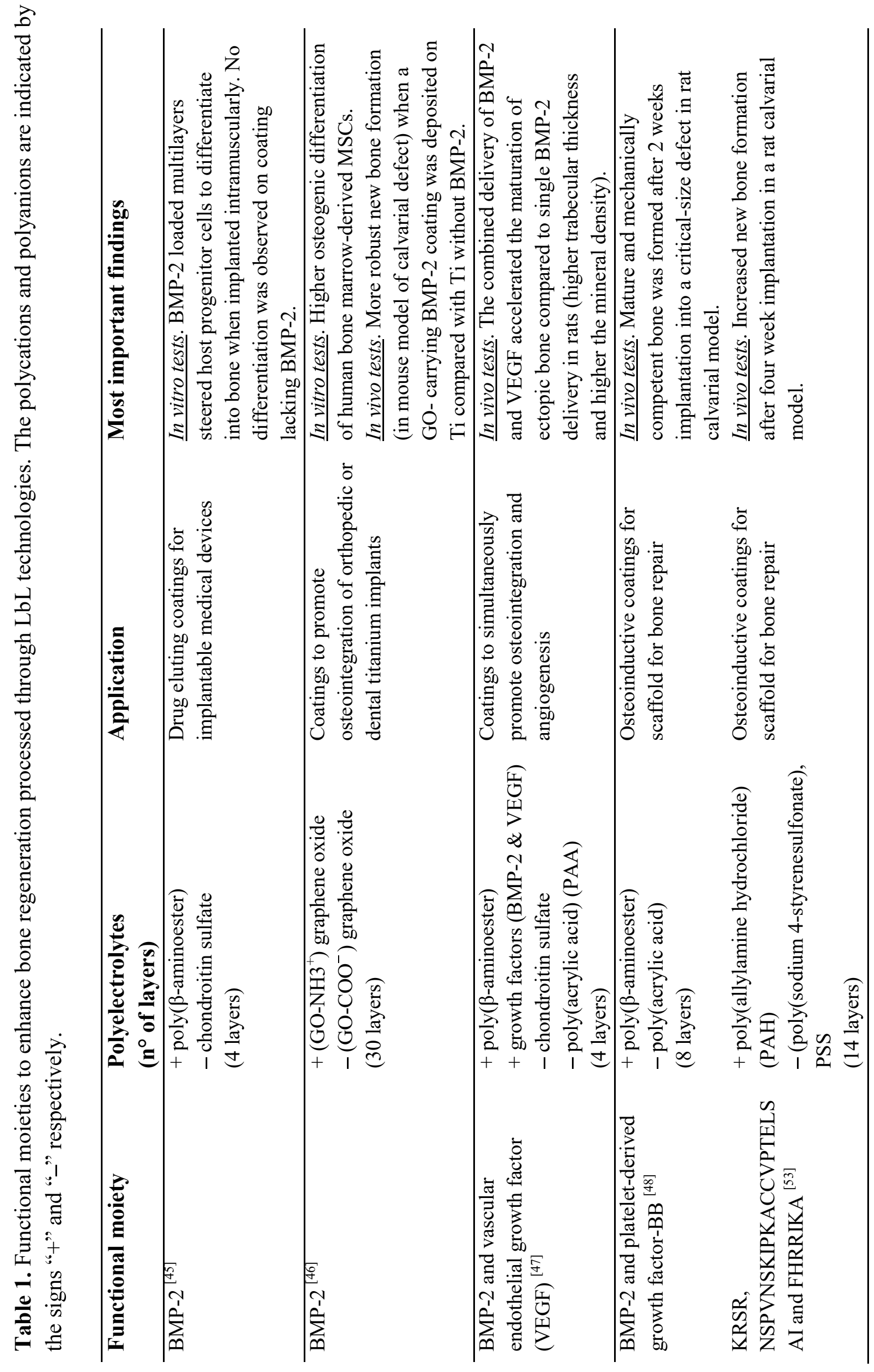

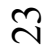




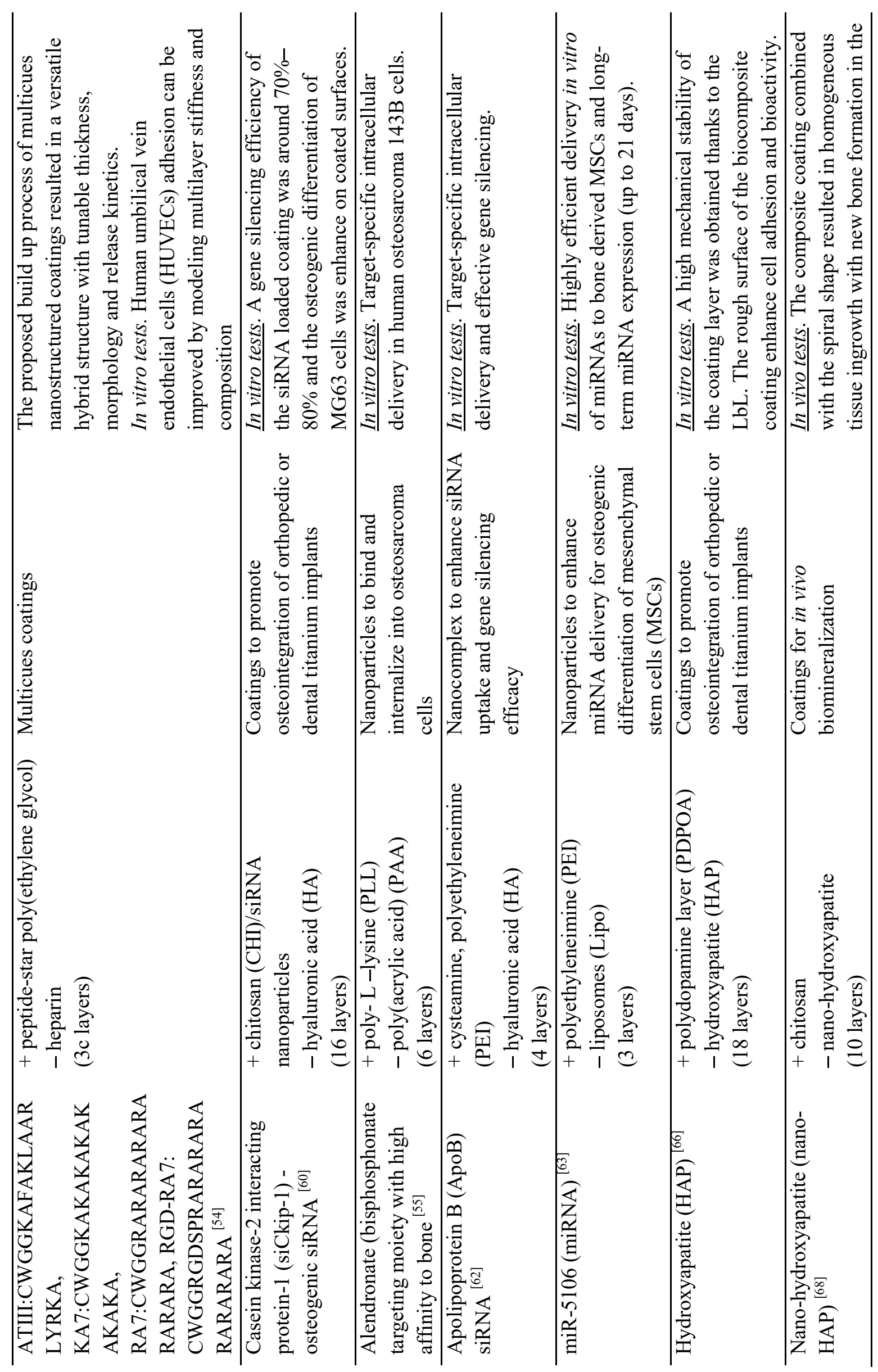

$\stackrel{\searrow}{\sim}$ 


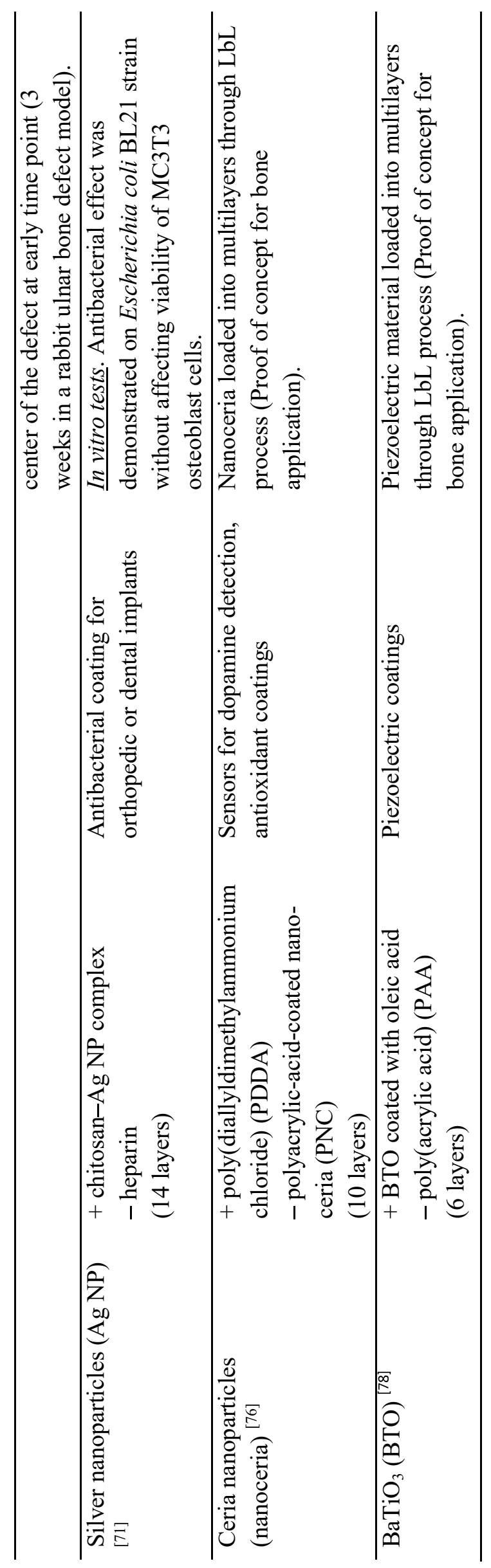




\section{References}

[1] K. B. Blodgett, I. Langmuir, Phys. Rev. 1937, 51, 964.

[2] J. J. Richardson, J. Cui, M. Björnmalm, J. A. Braunger, H. Ejima, F. Caruso, Chem. Rev. 2016, 116, 14828.

[3] F.-X. Xiao, M. Pagliaro, Y.-J. Xu, B. Liu, Chem. Soc. Rev. 2016, 45, 3088.

[4] J. Fu, J. B. Schlenoff, J. Am. Chem. Soc. 2016, 138, 980; P. Gentile, I. Carmagnola, T. Nardo, V. Chiono, Nanotechnology 2015, 26, 422001.

[5] J. Hong, H. Park, Colloids Surf. Physicochem. Eng. Aspects 2011, 381, 7.

[6] G. Decher, Science 1997, 277, 1232.

[7] J. J. Richardson, M. Björnmalm, F. Caruso, Science 2015, 348, aaa2491.

[8] B. S. Shim, P. Podsiadlo, D. G. Lilly, A. Agarwal, J. Lee, Z. Tang, S. Ho, P. Ingle, D. Paterson, W. Lu, Nano letters 2007, 7, 3266.

[9] C. Picart, F. Caruso, J.-C. Voegel, Layer-by-layer films for biomedical applications, John Wiley \& Sons, 2014.

[10] X. Wang, H. J. Kim, P. Xu, A. Matsumoto, D. L. Kaplan, Langmuir 2005, 21, 11335.

[11] P. Tryoen - Tóth, D. Vautier, Y. Haikel, J. C. Voegel, P. Schaaf, J. Chluba, J. Ogier, Journal of Biomedical Materials Research: An Official Journal of The Society for Biomaterials, The Japanese Society for Biomaterials, and The Australian Society for Biomaterials and the Korean Society for Biomaterials 2002, 60, 657.

[12] R. A. Perez, S.-J. Seo, J.-E. Won, E.-J. Lee, J.-H. Jang, J. C. Knowles, H.-W. Kim, Materials Today 2015, 18, 573.

[13] X.-Q. Liu, R.-Z. Tang, Drug delivery 2017, 24, 1.

[14] C. Allan, A. Ker, C.-A. Smith, P. M. Tsimbouri, J. Borsoi, S. O’Neill, N. Gadegaard, M. J. Dalby, R. Dominic Meek, Journal of tissue engineering 2018, 9, 2041731418784098.

[15] G. Abagnale, M. Steger, V. H. Nguyen, N. Hersch, A. Sechi, S. Joussen, B. Denecke, R. Merkel, B. Hoffmann, A. Dreser, Biomaterials 2015, 61, 316.

[16] X. Chen, H. Fan, X. Deng, L. Wu, T. Yi, L. Gu, C. Zhou, Y. Fan, X. Zhang, Nanomaterials 2018, 8, 960.

[17] V. Gribova, R. Auzely-Velty, C. Picart, Chemistry of Materials 2011, 24, 854.

[18] S. M. Oliveira, T. H. Silva, R. L. Reis, J. F. Mano, Journal of Materials Chemistry B 2013, 1, 4406.

[19] W. C. Liu, Y.-C. Lin, M. Xu, S. C. Nabilla, Y.-L. Lin, L.-C. Chen, R.-J. Chung, Surface and Coatings Technology 2018, 350, 755.

[20] M. T. Thompson, M. C. Berg, I. S. Tobias, M. F. Rubner, K. J. Van Vliet, Biomaterials 2005, 26, 6836; A. A. Chen, S. R. Khetani, S. Lee, S. N. Bhatia, K. J. Van Vliet, Biomaterials 2009, 30, 1113.

[21] Y. Liu, J. Xu, Y. Zhou, Z. Ye, W.-S. Tan, Materials Science and Engineering: C 2017, 78,579 .

[22] G. Berth, H. Dautzenberg, M. G. Peter, Carbohydrate Polymers 1998, 36, 205; J. Brugnerotto, J. Desbrières, G. Roberts, M. Rinaudo, Polymer 2001, 42, 09921.

[23] K. Cai, A. Rechtenbach, J. Hao, J. Bossert, K. D. Jandt, Biomaterials 2005, 26, 5960.

[24] J. A. Chapman, Biopolymers: Original Research on Biomolecules 1989, 28, 1367.

[25] J. Zhang, B. Senger, D. Vautier, C. Picart, P. Schaaf, J.-C. Voegel, P. Lavalle, Biomaterials 2005, 26, 3353.

[26] G. G. S. Grant, D. S. Koktysh, B. Yun, R. L. Matts, N. A. Kotov, Biomedical Microdevices 2001, 3, 301.

[27] A. M. Ferreira, P. Gentile, S. Toumpaniari, G. Ciardelli, M. A. Birch, ACS applied materials \& interfaces 2016, 8, 29923. 
[28] T. Miller, M. C. Goude, T. C. McDevitt, J. S. Temenoff, Acta biomaterialia 2014, 10, 1705 .

[29] M. Y. Zhao, L. H. Li, B. Li, C. R. Zhou, Express Polymer Letters 2014, 8.

[30] M. Zhao, L. Li, B. Li, C. Zhou, Express Polymer Letters 2014, 8.

[31] J.-X. He, W.-L. Tan, Q.-M. Han, S.-Z. Cui, W. Shao, F. Sang, Journal of materials science 2016, 51, 4399.

[32] H. Yan, X. Chen, M. Feng, Z. Shi, D. Zhang, Q. Lin, Materials Letters 2017, 209, 492.

[33] Z. Wang, X. Zhang, J. Gu, H. Yang, J. Nie, G. Ma, Carbohydrate polymers 2014, 103, 38.

[34] A. G. Guex, J. L. Puetzer, A. Armgarth, E. Littmann, E. Stavrinidou, E. P. Giannelis, G. G. Malliaras, M. M. Stevens, Acta biomaterialia 2017, 62, 91; E. Guzmán, A. MateosMaroto, M. Ruano, F. Ortega, R. G. Rubio, Advances in colloid and interface science 2017. [35] K. Cai, Y. Hu, K. D. Jandt, Y. Wang, Journal of materials science: Materials in medicine 2008, 19, 499.

[36] K. Cai, Y. Wang, Journal of Materials Science: Materials in Medicine 2006, 17, 929.

[37] N. Ostrowski, B. Lee, N. Enick, B. Carlson, S. Kunjukunju, A. Roy, P. N. Kumta, Acta Biomaterialia 2013, 9, 8704.

[38] X. Liu, F. Han, P. Zhao, C. Lin, X. Wen, X. Ye, Nanomedicine: Nanotechnology, Biology and Medicine 2017, 13, 1423.

[39] T. G. Vladkova, International Journal of polymer science 2010, 2010.

[40] X.-Q. Zhang, X. Xu, N. Bertrand, E. Pridgen, A. Swami, O. C. Farokhzad, Advanced drug delivery reviews 2012, 64, 1363.

[41] Z. Wang, W. Zhu, Y. Qiu, X. Yi, A. von dem Bussche, A. Kane, H. Gao, K. Koski, R. Hurt, Chemical Society Reviews 2016, 45, 1750.

[42] A. N. Zelikin, C. Ehrhardt, A. M. Healy, Nature chemistry 2016, 8, 997.

[43] I. El Bialy, W. Jiskoot, M. R. Nejadnik, Pharmaceutical research 2017, 34, 1152.

[44] Z. S. Haidar, R. C. Hamdy, M. Tabrizian, Biotechnology letters 2009, 31, 1817.

[45] M. L. Macdonald, R. E. Samuel, N. J. Shah, R. F. Padera, Y. M. Beben, P. T.

Hammond, Biomaterials 2011, 32, 1446.

[46] W. G. La, S. Park, H. H. Yoon, G. J. Jeong, T. J. Lee, S. H. Bhang, J. Y. Han, K. Char, B. S. Kim, Small 2013, 9, 4051.

[47] N. J. Shah, M. L. Macdonald, Y. M. Beben, R. F. Padera, R. E. Samuel, P. T. Hammond, Biomaterials 2011, 32, 6183.

[48] N. J. Shah, M. N. Hyder, M. A. Quadir, N.-M. D. Courchesne, H. J. Seeherman, M. Nevins, M. Spector, P. T. Hammond, Proceedings of the National Academy of Sciences 2014, $111,12847$.

[49] Y. W. Chen, F. Ding, H. F. Nie, A. W. Serohijos, S. Sharma, K. C. Wilcox, S. Y. Yin, N. V. Dokholyan, Arch Biochem Biophys 2008, 469, 4; M. Tallawi, E. Rosellini, N. Barbani, M. G. Cascone, R. Rai, G. Saint-Pierre, A. R. Boccaccini, J R Soc Interface 2015, 12 , 20150254.

[50] M. Hasenbein, T. T. Andersen, R. Bizios, Biomaterials 2002, 23, 3937.

[51] A. M. Wojtowicz, A. Shekaran, M. E. Oest, K. M. Dupont, K. L. Templeman, D. W. Hutmacher, R. E. Guldberg, A. J. García, Biomaterials 2010, 31, 2574.

[52] P. Gentile, C. Ghione, C. Tonda-Turo, D. M. Kalaskar, RSC Advances 2015, 5, 80039. [53] P. Gentile, A. M. Ferreira, J. T. Callaghan, C. A. Miller, J. Atkinson, C. Freeman, P. V. Hatton, Advanced healthcare materials 2017, 6, 1601182.

[54] A. K. Thomas, R. Wieduwild, R. Zimmermann, W. Lin, J. Friedrichs, M. Bickle, K. Fahmy, C. Werner, Y. Zhang, ACS applied materials \& interfaces 2018, 10, 14264.

[55] S. W. Morton, N. J. Shah, M. A. Quadir, Z. J. Deng, Z. Poon, P. T. Hammond, Advanced healthcare materials 2014, 3, 867.

[56] S. Ghadakzadeh, R. Hamdy, M. Tabrizian, Heliyon 2017, 3, e00450. 
[57] B. Bozdoğan, Ö. Akbal, E. Çelik, M. Türk, E. B. Denkbaş, RSC Advances 2017, 7, 47592.

[58] S. M. Sarett, C. E. Nelson, C. L. Duvall, Journal of Controlled Release 2015, 218, 94.

[59] A. Wittrup, J. Lieberman, Nature Reviews Genetics 2015, 16, 543.

[60] W. Song, X. Song, C. Yang, S. Gao, L. H. Klausen, Y. Zhang, M. Dong, J. Kjems, International journal of nanomedicine 2015, 10, 2335 .

[61] J. B. Lian, G. S. Stein, A. J. Van Wijnen, J. L. Stein, M. Q. Hassan, T. Gaur, Y. Zhang, Nature Reviews Endocrinology 2012, 8, 212.

[62] M.-Y. Lee, S.-J. Park, K. Park, K. S. Kim, H. Lee, S. K. Hahn, ACS nano 2011, 5, 6138.

[63] M. Yu, B. Lei, C. Gao, J. Yan, P. X. Ma, Nano Research 2017, 10, 49.

[64] A. B. Plonka, B. Khorsand, N. Yu, J. V. Sugai, A. K. Salem, W. V. Giannobile, S. Elangovan, Gene therapy 2017, 24, 31 .

[65] D. Zhang, X. Wu, J. Chen, K. Lin, Bioactive materials 2017.

[66] Y. Wu, X. Liu, Y. Li, M. Wang, RSC Advances 2014, 4, 44427.

[67] K. S. Schanze, H. Lee, P. B. Messersmith, ACS Publications, 2018.

[68] O. S. Manoukian, A. Aravamudhan, P. Lee, M. R. Arul, X. Yu, S. Rudraiah, S. G. Kumbar, ACS Biomaterials Science \& Engineering 2018, 4, 2181.

[69] W. G. De Long Jr, T. A. Einhorn, K. Koval, M. McKee, W. Smith, R. Sanders, T. Watson, The Journal of bone and joint surgery. American volume 2007, 89, 649 .

[70] S. T. Dubas, P. Kumlangdudsana, P. Potiyaraj, Colloids and Surfaces A: Physicochemical and Engineering Aspects 2006, 289, 105.

[71] J. Fu, J. Ji, D. Fan, J. Shen, Journal of Biomedical Materials Research Part A: An Official Journal of The Society for Biomaterials, The Japanese Society for Biomaterials, and The Australian Society for Biomaterials and the Korean Society for Biomaterials 2006, 79, 665.

[72] G. G. Genchi, A. Marino, A. Grillone, I. Pezzini, G. Ciofani, Advanced healthcare materials 2017, 6, 1700002 .

[73] A. Marino, C. Tonda-Turo, D. De Pasquale, F. Ruini, G. Genchi, S. Nitti, V. Cappello, M. Gemmi, V. Mattoli, G. Ciardelli, Biochimica et Biophysica Acta (BBA)-General Subjects 2017, 1861, 386.

[74] M. P. Souza, A. F. Vaz, T. B. Costa, M. A. Cerqueira, C. M. De Castro, A. A. Vicente, M. G. Carneiro-da-Cunha, Food and Bioprocess Technology 2018, 11, 1050.

[75] A. Karakoti, N. Monteiro-Riviere, R. Aggarwal, J. Davis, R. J. Narayan, W. Self, J. McGinnis, S. Seal, Jom 2008, 60, 33.

[76] X. Zhang, B. Wang, X. Zhang, T. He, Sensors and Actuators B: Chemical 2012, 166, 695.

[77] B. Tandon, J. J. Blaker, S. H. Cartmell, Acta biomaterialia 2018.

[78] Y. Kim, K. Y. Lee, S. K. Hwang, C. Park, S. W. Kim, J. Cho, Advanced Functional Materials 2014, 24, 6262.

[79] E. Verron, H. Schmid-Antomarchi, H. Pascal-Mousselard, A. Schmid-Alliana, J.-C. Scimeca, J.-M. Bouler, Drug discovery today 2014, 19, 1419; H. Ma, C. Jiang, D. Zhai, Y. Luo, Y. Chen, F. Lv, Z. Yi, Y. Deng, J. Wang, J. Chang, Advanced Functional Materials 2016, 26, 1197.

[80] A. Luetke, P. A. Meyers, I. Lewis, H. Juergens, Cancer treatment reviews 2014, 40, 523.

[81] A. S. Thakor, S. S. Gambhir, CA: a cancer journal for clinicians 2013, 63, 395.

[82] C. Mauffrey, B. T. Barlow, W. Smith, JAAOS-Journal of the American Academy of Orthopaedic Surgeons 2015, 23, 143.

[83] J. Shi, P. W. Kantoff, R. Wooster, O. C. Farokhzad, Nature Reviews Cancer 2017, 17, 20. 
[84] M. Ferrari, Nature Reviews Cancer 2005, 5, 161.

[85] A. Elbakry, A. Zaky, R. Liebl, R. Rachel, A. Goepferich, M. Breunig, Nano letters 2009, 9, 2059; G. F. Schneider, V. Subr, K. Ulbrich, G. Decher, Nano letters 2009, 9, 636. [86] E. M. Saurer, C. M. Jewell, J. M. Kuchenreuther, D. M. Lynn, Acta biomaterialia 2009, 5, 913; A. L. Becker, A. P. R. Johnston, F. Caruso, Small 2010, 6.

[87] C. H. J. Choi, C. A. Alabi, P. Webster, M. E. Davis, Proceedings of the National Academy of Sciences 2010, 107, 1235.

[88] M. M. J. Kamphuis, A. P. R. Johnston, G. K. Such, H. H. Dam, R. A. Evans, A. M. Scott, E. C. Nice, J. K. Heath, F. Caruso, Journal of the American Chemical Society 2010, $132,15881$.

[89] D. Neri, C. T. Supuran, Nature reviews Drug discovery 2011, 10, 767.

[90] X. L. Wu, J. H. Kim, H. Koo, S. M. Bae, H. Shin, M. S. Kim, B.-H. Lee, R.-W. Park, I.-S. Kim, K. Choi, Bioconjugate chemistry 2010, 21, 208.

[91] Z. Poon, D. Chang, X. Zhao, P. T. Hammond, ACS nano 2011, 5, 4284.

[92] H. P. Lesch, M. U. Kaikkonen, J. T. Pikkarainen, S. Ylä-Herttuala, Expert opinion on drug delivery 2010, 7, 551.

[93] F. Alexis, E. Pridgen, L. K. Molnar, O. C. Farokhzad, Molecular pharmaceutics 2008, 5,505 .

[94] H. Maeda, J. Wu, T. Sawa, Y. Matsumura, K. Hori, Journal of controlled release 2000, $65,271$.

[95] K. Liang, G. K. Such, A. P. R. Johnston, Z. Zhu, H. Ejima, J. J. Richardson, J. Cui, F. Caruso, Advanced Materials 2014, 26, 1901.

[96] L. Cheng, C. Wang, L. Feng, K. Yang, Z. Liu, Chemical reviews 2014, 114, 10869; L. Cheng, W. He, H. Gong, C. Wang, Q. Chen, Z. Cheng, Z. Liu, Advanced Functional Materials 2013, 23, 5893.

[97] Y. Yong, L. Zhou, S. Zhang, L. Yan, Z. Gu, G. Zhang, Y. Zhao, NPG Asia Materials 2016, 8, e273.

[98] L. Cheng, K. Yang, Q. Chen, Z. Liu, ACS nano 2012, 6, 5605.

[99] M. Vosgueritchian, D. J. Lipomi, Z. Bao, Advanced functional materials 2012, 22, 421; D. Khodagholy, T. Doublet, M. Gurfinkel, P. Quilichini, E. Ismailova, P. Leleux, T. Herve, S. Sanaur, C. Bernard, G. G. Malliaras, Advanced Materials 2011, 23, H268.

[100] H. Otsuka, Y. Nagasaki, K. Kataoka, Advanced drug delivery reviews 2012, 64, 246.

[101] X. Wang, T. Li, H. Ma, D. Zhai, C. Jiang, J. Chang, J. Wang, C. Wu, NPG Asia Materials 2017, 9, e376.

[102] K. A. Whitehead, R. Langer, D. G. Anderson, Nature reviews Drug discovery 2009, 8, 129.

[103] J. Gilleron, W. Querbes, A. Zeigerer, A. Borodovsky, G. Marsico, U. Schubert, K. Manygoats, S. Seifert, C. Andree, M. Stöter, Nature biotechnology 2013, 31, 638; Z. u. Rehman, D. Hoekstra, I. S. Zuhorn, ACS nano 2013, 7, 3767.

[104] D. K. Bonner, C. Leung, J. Chen-Liang, L. Chingozha, R. Langer, P. T. Hammond, Bioconjugate chemistry 2011, 22, 1519.

[105] T.-M. Sun, J.-Z. Du, Y.-D. Yao, C.-Q. Mao, S. Dou, S.-Y. Huang, P.-Z. Zhang, K. W. Leong, E.-W. Song, J. Wang, ACS nano 2011, 5, 1483.

[106] J. E. Zuckerman, C. H. J. Choi, H. Han, M. E. Davis, Proceedings of the National Academy of Sciences 2012, 109, 3137.

[107] T. Lobovkina, G. B. Jacobson, E. Gonzalez-Gonzalez, R. P. Hickerson, D. Leake, R. L. Kaspar, C. H. Contag, R. N. Zare, ACS nano 2011, 5, 9977.

[108] Y. Zhang, N. M. J. Schwerbrock, A. B. Rogers, W. Y. Kim, L. Huang, Molecular Therapy 2013, 21, 1559; O. Taratula, A. Kuzmov, M. Shah, O. B. Garbuzenko, T. Minko, Journal of Controlled Release 2013, 171, 349. 
[109] Z. J. Deng, S. W. Morton, E. Ben-Akiva, E. C. Dreaden, K. E. Shopsowitz, P. T. Hammond, ACS nano 2013, 7, 9571.

[110] M. Keeney, X. Jiang, M. Yamane, M. Lee, S. Goodman, F. Yang, Journal of Materials Chemistry B 2015, 3, 8757.

[111] P. T. Hammond, Materials Today 2012, 15, 196.

[112] B. B. Hsu, S. R. Hagerman, P. T. Hammond, Journal of applied polymer science 2016, 133.

[113] M. B. Oliveira, J. Hatami, J. F. Mano, Chemistry-An Asian Journal 2016, 11, 1753.

[114] J. T. Wilson, W. Cui, V. Kozlovskaya, E. Kharlampieva, D. Pan, Z. Qu, V. R.

Krishnamurthy, J. Mets, V. Kumar, J. Wen, Journal of the American Chemical Society 2011, 133, 7054.

[115] V. Kozlovskaya, S. Harbaugh, I. Drachuk, O. Shchepelina, N. Kelley-Loughnane, M. Stone, V. V. Tsukruk, Soft Matter 2011, 7, 2364.

[116] Y. Z. Wang, J. M. Plane, P. Jiang, C. J. Zhou, W. Deng, Stem Cells 2011, 29, 907.

[117] D. J. Donnelly, P. G. Popovich, Experimental neurology 2008, 209, 378.

[118] J. G. Tidball, M. Wehling - Henricks, The Journal of physiology 2007, 578, 327.

[119] A. Haisch, A. Gröger, C. Radke, J. Ebmeyer, H. Sudhoff, G. Grasnick, V. Jahnke, G. Burmester, M. Sittinger, Biomaterials 2000, 21, 1561.

[120] D. Huh, Y.-s. Torisawa, G. A. Hamilton, H. J. Kim, D. E. Ingber, Lab on a Chip 2012, 12, 2156; S. Bersini, J. S. Jeon, G. Dubini, C. Arrigoni, S. Chung, J. L. Charest, M. Moretti, R. D. Kamm, Biomaterials 2014, 35, 2454.

[121] J. Hoarau-Véchot, A. Rafii, C. Touboul, J. Pasquier, International journal of molecular sciences 2018, 19, 181.

[122] E. Cenni, F. Perut, N. Baldini, Acta Pharmacologica Sinica 2011, 32, 21.

[123] C. Correia, W. L. Grayson, M. Park, D. Hutton, B. Zhou, X. E. Guo, L. Niklason, R. A.

Sousa, R. L. Reis, G. Vunjak-Novakovic, PloS one 2011, 6, e28352.

[124] J. M. Kanczler, R. O. Oreffo, Eur Cell Mater 2008, 15, 100.

[125] M. Akashi, T. Akagi, M. Matsusaki, Engineered Cell Manipulation for Biomedical Application, Springer, 2014.

[126] B. Thierry, F. M. Winnik, Y. Merhi, M. Tabrizian, Journal of the American Chemical Society 2003, 125, 7494.

[127] E. Seeman, P. D. Delmas, New England journal of medicine 2006, 354, 2250.

[128] A. Csordas, A. E. Gerdon, J. D. Adams, J. Qian, S. S. Oh, Y. Xiao, H. T. Soh, Angewandte Chemie International Edition 2010, 49, 355.

[129] S. Shetty, N. Kapoor, J. D. Bondu, N. Thomas, T. V. Paul, Indian journal of endocrinology and metabolism 2016, 20, 846.

[130] B. V. Chikkaveeraiah, A. A. Bhirde, N. Y. Morgan, H. S. Eden, X. Chen, ACS nano 2012, 6, 6546 .

[131] C. Moß, N. Weinrich, K. Seide, J. Müller, "Wireless recording system for long-term monitoring of bone fracture healing", presented at World Congress on Medical Physics and Biomedical Engineering, September 7-12, 2009, Munich, Germany, 2009.

[132] L. Shi, Y. Lu, J. Sun, J. Zhang, C. Sun, J. Liu, J. Shen, Biomacromolecules 2003, 4, 1161.

[133] M. M. Kamphuis, A. P. Johnston, G. K. Such, H. H. Dam, R. A. Evans, A. M. Scott, E. C. Nice, J. K. Heath, F. Caruso, Journal of the American Chemical Society 2010, 132, 15881.

[134] S. A. Castleberry, W. Li, D. Deng, S. Mayner, P. T. Hammond, ACS nano 2014, 8, 6580 . 